\title{
Agricultural adaptation to climate change in the trans-Himalaya: a study of Loba Community of Lo-manthang, Upper Mustang, Nepal
}

\author{
Man Bahadur Khattri - Rishikesh Pandey $(\mathbb{D}$
}

Received: 18 May 2020 / Accepted: 5 November 2020 / Published online: 12 January 2021 (C) The Author(s). 2021 Open Access This article is licensed under a Creative Commons Attribution 4.0 International License, which permits use, sharing, adaptation, distribution and reproduction in any medium or format, as long as you give appropriate credit to the original author(s) and the source, provide a link to the Creative Commons licence, and indicate if changes were made. The images or other third party material in this article are included in the article's Creative Commons licence, unless indicated otherwise in a credit line to the material. If material is not included in the article's Creative Commons licence and your intended use is not permitted by statutory regulation or exceeds the permitted use, you will need to obtain permission directly from the copyright holder. To view a copy of this licence, visit http://creativecommons.org/licenses/by/4.0/.

\begin{abstract}
This paper presents community interference on agricultural ecology against climate change impacts in Lo-manthang, Upper-Mustang, Nepal. The peoples' response strategies are based on traditional agroecological knowledge. This study applied the human ecological approach (Cause $\rightarrow$ Effect $\rightarrow$ Response) to analyze continuity and change in the agricultural practice of the indigenous Loba community of the Trans-Himalaya. Data were generated through anthropological fieldwork using quasi-ethnomethodology. Qualitative data on changing climate was further supported by the analysis of meteorological records of last 40 years from the nearest station. The overall impression of the study is that the Lobas are hardly adapting to the dynamics of socio-environmental factors as climatic, geo-environmental, and politico-institutional changes. The strategy adopted to respond to the impacts of change on the local livelihoods is particularly associated with altering traditional agricultural practices. Indigenous knowledgebased systems of farm, labor, and resource management, accompanied by changes in food preference (food value) and linking agriculture with spiritual practice, are specific adaptation options, further supported by emerging options such as occupational modernization and migration. However, not all of these strategies produced positive outcomes in the local socio-ecological system of Lo-manthang.
\end{abstract}

M.B. Khattri $(\square)$

Central Department of Anthropology, Tribhuvan University, Kathmandu, Nepal

e-mail: mankhattri@gmail.com

R. Pandey

School of Development and Social Engineering, Pokhara University, Pokhara, Nepal 
Therefore, policymakers should recognize Trans-Himalayan environmental uniqueness and its sensitivity to different drivers while designing policy to address them.

Keywords Agricultural adaptation - Climate change - Loba community · Nepal · Social-ecology $\cdot$ Trans-Himalaya $\cdot$ Upper-mustang

\section{Introduction}

Changes in climate systems have been impacting everything that humans have a concern. Its catastrophic impacts on marine, freshwater, and terrestrial life, from plankton and corals to fishes and forests, have been projected and also already started to be experienced (Gills \& Morgan, 2020; IPCC 2018; IPCC 2019; Ripple et al., 2019). The rate of change in the climate system inhibits spatial and seasonal characteristics (Pandey 2016a) that partially fueled to climate skeptics (Kaufmann et al. 2017). The impacts are also variable across the social-ecological systems because of differential exposure to the rate of change, level of sensitivity of the systems, and adaptive capacity of an ecological system to the drivers of change (Pandey and Bardsley 2019). The climate system of the Himalaya is changing faster than that of the global average, and in the variable rates within the region (Pandey 2016a; Pandey 2016b; Shrestha et al. 2012; Wester et al. 2019). Such change has affected the poor people of the Himalaya and vicinity socially, emotionally, and economically (Bhatta et al. 2015; Chhetri et al. 2013; Macchi et al. 2015). Agriculture is the primary livelihood option of the Himalayan people, and it is highly sensitive to climate change (Pandey 2019a). However, estimations indicate that crop yields could decrease up to $30 \%$ in South Asia by the end of the twentyfirst century, even if the direct positive physiological effects of $\mathrm{CO}_{2}$ are taken into account (Cruz et al. 2007). The effects of climate change in agricultural-based livelihoods have already been visible in the parts of the Himalaya. Increased crop pests and diseases, as well as farm weeds reduce crop yields (Gentle et al. 2014; Palazzoli et al. 2015); and there are evidences of farmland loss, its abandonment, and decline in farm productivity due to extreme weather events (Chhetri and Easterling 2010; Fort 2015; Pandey 2019b). However, there is very limited study about this highly diverse social ecosystems. The trans-Himalaya is the most isolated region, which is also the climate-sensitive region having cool and dry climatic conditions.

The regions, such as Upper Mustang and Manang, have been largely excluded from mainstream research, particularly due to areas' inaccessibility and remoteness, as well as the requirement of a special permit to conduct research works by foreigners (Pandey 2017). There is a clear knowledge gap and this study attempts to fill the knowledge gap, by exploring the climate change impact on agriculture system of the Lo-manthang. This study will also present the map of the indigenous adaptation efforts. This research uses a human ecological approach to understand human-environmental interactions and develops policy feedback to reduce poverty and hunger in the Trans-Himalaya as a part of the response to climate change impacts. 
This paper is structured into five sections. The introduction section provides research theme and research aim, followed by the conceptualization of the research theme from a human ecological perspective in the second section. The third section provides data and methods used, while in the fourth section, results are presented in relation to the existing scholarship in the field. This section firstly elaborates the social-environmental setting of the study area, followed by climate change impacts and indigenous adaptation efforts. The final section concludes the research work and recommends for policy feedback and further research agenda.

\section{Conceptualizing climate change impacts from a human ecological perspective}

Human ecology is one of the foremost science, which is often divided into several specialized areas such as cultural ecology (Steward 1977), political ecology as applied initially by Cockburn, Wolf and Beakhurst in the 1970s (Watts 2009); environmental psychology (Kitchin and Blades 2002); and social ecology (Berkes and Folke 1998; Bookchin 1995). A human ecological approach is a culturalgeographic way of inquiring human-environmental interactions. It is the science of ecology that explains the complex and dynamic interrelations between societal and biophysical systems (Barrows 1923; Lawrence 2003; Prudham 2009). Societies develop a complex but systematic interaction with the environment, and climate has always been a crucial negotiating component. Therefore, the human ecological approach provides a meaningful way of understanding of the social-ecological system of a particular ecosystem. The social-ecological system explains the complex and interactive interrelationships of social phenomena within the biophysical environments and the political-economic, cultural, institutional, and technological trajectories of social development (Adger 2000; Berkes and Folke 1998; Capra 2007). Since social ecology stresses for a transformative social and environmental system that links humanity with the environment both systematically and holistically. It can be viewed as an approach or paradigm of viewing social and environmental systems. In recent decades, social ecology has been interpreted as an alternative to or advanced form of human ecology that steps further to state the expected humanenvironmental interrelationship for the sake of social-ecological sustainability (Pandey and Bardsley 2019).

In the discipline of human ecology, the concept 'adaptation' is applied as a viable approach to interpreting interrelationship between culture and environment. According to Steward, "culture core" illustrate people's subsistence, mainly technology, economic arrangement and social organization in relation to environmental condition. Orlove (1980) has presented a history of ecological anthropology in three broad stages. Firstly, the 1930-1960s or the work of Steward (1955) and White (1959); Secondly, the 1960s - early 1970s with the work of Elman Service (1962), Karl Polanyi (1957), Marvin Harris (1975), Andrew P. Vayda (1974), and Roy Rappaport (1967), with focus ion to neoevolutionism and neo-functionalism. Thirdly, the post-1980s, which is considered to be the period of disciplinary advancement through multiple works. In this period, human ecologists adopted processual approaches, and they focus 
on population and environmental interaction (Orlove 1980). Human ecology, by its nature, belongs to the third stage of ecological anthropology that has lately recognized the role of place, space, and environment into the study of human-environmental interaction.

Human ecology is the science that originated from the discipline of ecology and applied to study human society and culture in relation to the natural environment (Kassam 2009; Little 2007). It also includes areas of ecological and environmental anthropology (Sutton and Anderson 2010). Vayda (1983) used a human ecological approach to develop cultural ecologies with a broader and higher approaches, with the inclusion of several aspects such as research unit, the problem of understanding the stability of units and systems, latitude of time, efforts, and money, so the results become significant for planners. This approach in human ecology allows us to look at the local environmental dynamic, resource status, and scale-specific influence of political and economic development. In the human ecological study, the population of a specific ecological system is considered as a unit of analysis (Hardesty 1975; Vayda 1983). Human ecologists give high priority to study resources, socio-cultural opportunities, and constrain on the livelihoods; consider humans as rational choosers; and the implication of political processes and historical ecological practices onto human-environmental interactions (Sutton and Anderson 2009). Human ecology is understood as "holistic, interdisciplinary, humanistic, spiritual, subversive, and connective one that is committed for synthesizing and transcendental studies; eschews chauvinism but accepts subjective reality and denies orthodox environmental determinism" (Kassam 2009).

Human ecology has adopted several approaches of ecologies such as political, evolutionary, historical, landscape, ecosystems, and the ecology of health and adaptability, as well as the ecology of reproduction since the 1980s (Little 2007). Prior to the issue of climate change entered into anthropological works, local resource availability, ecological conditions, altitude, soil fertility, water availability, and cultural complexities were the prime aspects of investigations in relation to analyzing distinct cultural evolution and development. Anthropologists began to analyze non-local factors that influence the local environment in the field of planning and policy interventions. Their research also covers the local environment and the development of socio-cultural systems by nation-states and global communities. Practically political ecology has become a convincing approach to adapt new fields since 1980s.

Anthropology of climate change is a newly developed field of study as it has been a major driver of environmental policymaking in the last three decades. Anthropologists are working on different aspects of climate change, such as indigenous perception, adaptation, resilience, mitigation, the anticipation of vulnerability, risk, and uncertainty, consumption, gender, migration, and displacement. They have also focused on cross-cutting issues such as inequality, health, carbon trading, and politics of climate change (Crate and Nuttall 2016). In this study, we have focused on adaptation to climate change impacts, particularly on to agriculture-based livelihood system of the environmentally sensitive Lo-manthang area of the TransHimalaya. 


\section{Methods and data}

This study has adopted a qualitative approach to conduct an anthropological research. Data are collected under the Ph.D. research project of the corresponding author. The anthropological fieldwork, using an emic approach, was adopted, and field visits in Upper-Mustang have been carried out multiple times between 2012 and 2015, and follow-up visits afterward. This research analyzes meteorological data, particularly the rainfall and temperature records, of the nearest weather station. Meteorological data are used from 1973 to 2015. The meteorological records were obtained from the Department of Hydrology and Meteorology, Government of Nepal; however, there was data gaps from 1989to 2005, which were bridged through extrapolation/projection based on the data of previous years (1974-1988).

The observation technique was one of the principal methods adopted to collect primary data, followed by the adoption of Key Informant Interviews (KII). Altogether 15 farmers, 5 lamas (the religious leaders), 1 amchi (traditional healers) were interviewed as key informants. Additionally, local scholars and representatives of Non-governmental Organizations (NGO) working in the agriculture sector of Upper-Mustang were also consulted. Review of literature on the related themes was another strategy to collect secondary information. The collected data and information are interpreted, and the necessary explanations is developed as required.

The data are analyzed using a context-specific interpretation of the stories, which are further supported by observed evidences. The meteorological data are analyzed using trend analysis and regression statistics. The LINEST statistics were used to identify the rate of change in temperature and rainfall.

\section{Analysis and discussion}

\section{Environmental setting of upper-mustang}

Nepal has three major ecological zones: the mountain, hill, and Tarai (plain), yet each of the regions have multiple sub-regions as the country is highly diverse geographically. These regions variably experience different hazards and environmental events. Upper-Mustang lies in the Trans-Himalaya, the rain-shadow of the Dhaulagiri and Annapurna Mountains Ranges, and at the upper Kaligandaki Basin (Fig. 1). The river has developed the world's deepest gorge at Dana, between Annapurna (south) and Dhawalagiri mountains, while flowing towards the south after originating in Tibet. The human settlements in Upper-Mustang are located between $2950 \mathrm{~m}$ above sea level (masl) to 3900 masl. Administratively, the Upper-Mustang, which is also known as the 'forbidden kingdom of the Himalaya' (Peissel 1992), covers an area of around 2565 Square Kilometer (DDC Mustang 2068).

The Trans-Himalaya lies in the northern foothills of the Greater Himalaya and the southern frontier of the Tibetan plateau. Climatically, this region is the rainshadow of the Greater Himalaya. Consequently, the area receives annual average precipitation of only $267 \mathrm{~mm}$ at Jomsom (Pandey 2016b) and $200.8 \mathrm{~cm}$ at Chhoser meteorological station. The East-West strip of the Trans-Himalaya in Nepal is 
interrupted by the Greater Himalaya, and Manang-Mustang block is the biggest block that lies inside Nepal. The maximum and minimum temperatures at Jomsom are about 15 and 8 degrees Celsius (average of 1971-2010), while they were 25 and-20 degrees Celsius, respectively, at Chhoser in 2013. The region has the cool-temperature arid climate; however, it frequently experiences at mid-latitude high-pressure belts and associated extreme blizzards.

The area lacks irrigation and is mostly covered by barren and rugged topography. The cultivated farmland is limited; however, small fields are managed almost as fertile oases. Therefore, the place is called 'Mustang' which means 'fertile plain' in Mustangi dialects (Pandey 2016b). The people of Lo-manthang are the Loba community, the inhabitants of Lo tsho-dhun. The region comprises subalpine scanty vegetation, alpine pastures, and some planted orchards. The primary economic activities are agro-livestock based, together with tourism (hospitality, trekking, and transportation) and seasonal business (hawking) to western and Midwestern hills areas of Nepal and cities of India. The region has only one growing season, April to September.

Upper-Mustang (Fig. 1) is connected by recently constructed seasonal unpaved roads. Public transport (jeep) is available occasionally if the weather is favorable. Jomsom is the nearest town, which is connected by air-route to Pokhara (city) and by road to Beni Bazaar (town). Pokhara is another next city where many Loba communities have settled and do seasonal business. The region was isolated not only from the outer world but also from the mainstream societies and governance systems of Nepal for many years. Marriage, family, language, the religion of Lomanthang are similar to Tibetan culture. Because of the area's remoteness and low population density, Lo-manthang lacks an effective supply of essential services such as health and education.

Agricultural system of Lo-manthang

The primary livelihoods of Loba community is an agro-pastoral system facilitated by only a growing season annually, which is further supported by trade and tourism entrepreneurship, particularly widened since 1992. Because of the single cropping season, farmer cultivates only a few varieties of crops. Agriculture is mostly rain-fed, with partial glacier-fed irrigation. The traditional agricultural practice of Lo-manthang is unique in the sense that individual farmers are not the independent decision-makers of their farm activities. Their community leader 'Ghenpa makes community-level decisions (defines days/dates) to begin specific tasks of the farming system - sowing and harvesting. In Upper-Mustang, there is quite short, but peak sowing and harvesting periods. This sort of practice, in some regards, causes temporary scarcity of water for irrigation and an inadequate supply of farm labor.

Loba community had been using the traditional tools and methods (Fig. 2); however, they are also incorporating modern tools and technologies in agriculture. Due to high altitude, area frequently hit by snowfall and northern blizzard, cause a severe drop in temperature - far below to freezing point. During such season, the Loba people migrate to warmer regions of southern Nepal. Some of them also visit India and engaged in seasonal trade. Those migrants often adopt hawking business, and the items they 
sell include woolen, herbal/medicinal, and aromatic products. In recent days, they also sell Tibetan ornaments and decorative from other ethnic groups of China.

Seasonal migration to warmer places is a mechanism that has helped Loba people to be benefited from the common resources other than their cultivated land.

The agriculture system of the Loba community of Lo-manthang is a complex integration of humans, animals, plants, and their habitats, therefore understanding ofo human ecology is essential. However, the agriculture system is strongly affected by weather conditions, soil nutrients, availability of labor, livestock management skill, and seed, as well as landholding size and the land tenure system of a place. Furthermore, the availability and use of pastureland, sources of fuel, food consumption practice, labor exchange and migration system, and practice of bartered economy is also implicate agricultural ecology both positively and negatively.

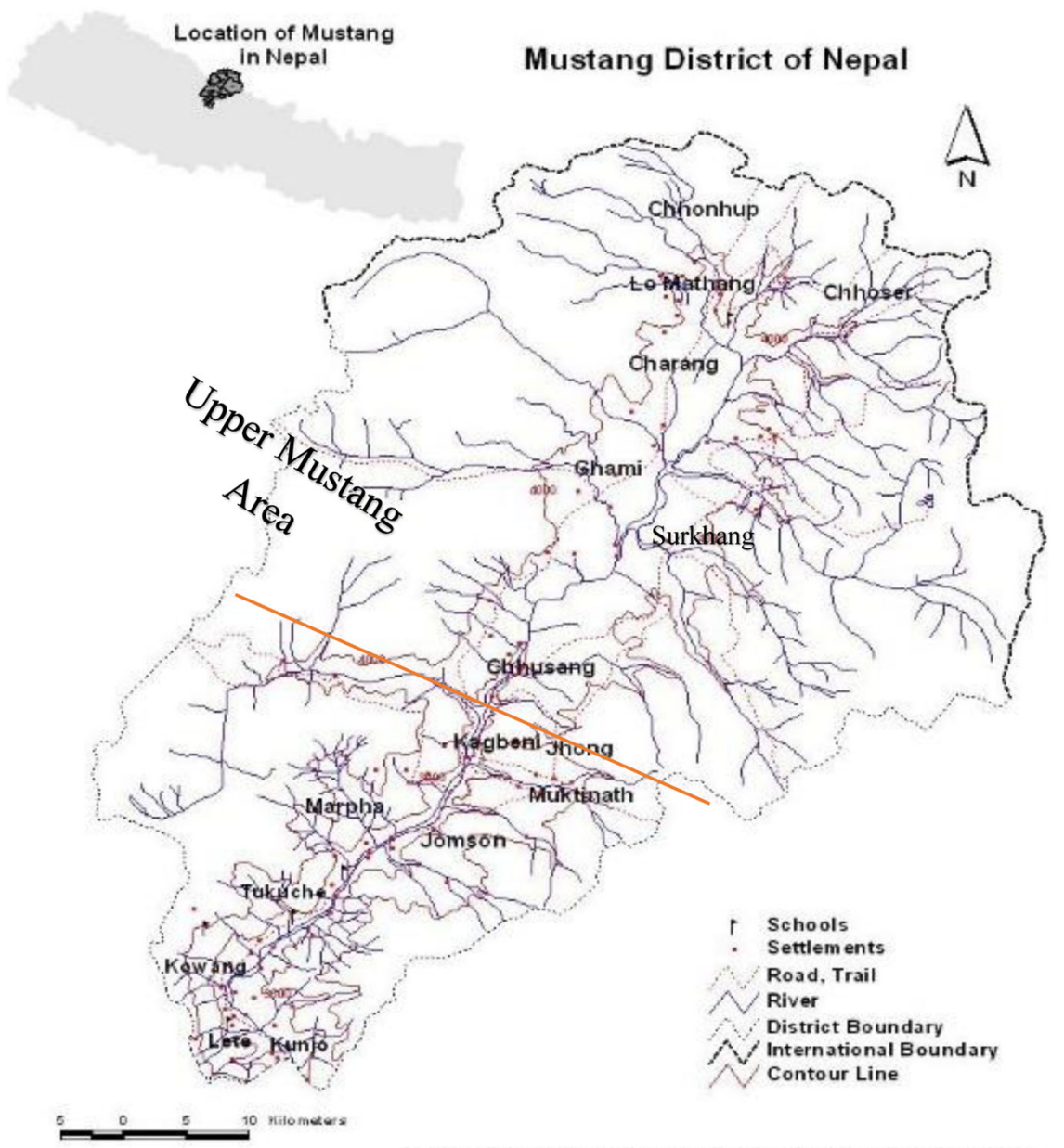

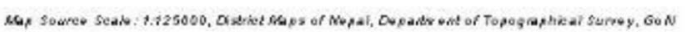

Fig. 1 Map of Upper Mustang, Nepal 
Therefore, we have collected and analyzed the information on the mentioned issues to develop an understanding of human-environmental interaction in Lo-manthang.

Social setting of upper-mustang, Lo-manthang

The local livelihood system of the Loba community of Lo-manthang is developed by utilizing the Trans-Himalayan niche. The niche also has determined the local socio-ecological system of the place and the community. Culturally and ethnically, the Lobas are of Tibetan origin, and their identity is constructed with reference to their socio-economic, cultural, linguistic, and historical context as well as geographic specificity of the location. The Lobas are indigenous people of Lo tshodhun. Etymologically, 'Lo tsho-dhun' refers to seven local councils of Mustang district, namely: Lo-manthang, Chhoser, Chonhup, Tsharang, Ghami, Surkhang, and Chhuksang, although 'Lo tsho-dhun' recently has been restructured into two Palikas (local government councils), namely Lo-manthang and Dalome rural municipalities.

Lo-manthang was the capital of Lo kingdom or Lo tsho-dhun until 2008. History informs us that since 1440 Lo-manthang became an independent kingdom from Nangri Tibet, and in 1788, it is included in the modern kingdom of Nepal (Dhungel 2002). However, Lo kingdom was under suzerain status. The suzerain status of the official Loba kingdom ended when the Kingdom of Nepal became a republic. The changes in the status of the petty kingdom of Lo tsho-dhun still have a significant influence on the social and political environment at the local level. It also affects intra and inter-community interactions, relations, and reciprocity within Upper-Mustang. The king of Lo lost his de facto kinghood of the region since 1952 after accepting the Lt. Colonel position in the Nepal Army (Bista 2004).

The identity of Lobas lies in different spheres of their lives. From a spiritual and religious aspect, the life of Lobas is known as Tibetan Buddhist. However, the Lobas follow different sects/schools of Tibetan Buddhism, with Sakyapa sect is the dominant one. Sakyapa sect follows the celibacy of monk and nun, especially the second child of the family. They had adopted the polyandry marriage system, linguistically, speak Loba language of Phalke dialect, which is slimier to the western Tibetan language (as per local seniors). The Tenchi has become a ritual identity of Lobas, which is performed to ward-off the possible disaster in the community, household, and to individuals. They follow sky-burial for their dead as a mortuary rite. This practice can be explained as the response to the hardship of managing dead-body in the cold climate of high altitude. On the other hand, sky-burial provides food for mountain eagles that reduces their frequency of hunting mountain goats for food. The demographic situation and cultural practices of Lobas, hence are deeply rooted in the environmental conditions of the region.

The Upper-Mustang is among the sparest populates regions in Nepal, having a density of only 1.49 persons per $\mathrm{km}^{2}$. The total population of the Lobas of UpperMustang is 3834 in 1104 households. The population and household of Lobas have been decreased by a decadal ratio of $1.40 \%$ and $1.14 \%$, respectively (CBS 2012a, $2012 b$ ). In the case of Lo-manthng, there are only 172 households, with a total population of 569 , in which females constitute 293 , slightly more than a half (CBS 
2012). This sort of negative population dynamics is also revealed by the high rate of out-migration (19\%) from the mountain region of Nepal (Suwal 2014). The sparsely populated area with people practicing celibacy and polyandry on the one hand and high rate of out-migration on the other cumulatively explain the existence of weak human-environmental interaction in the region that human intervention into the natural environment is limited to a lower scale (Pandey 2013).

The social position of an individual or household is vital in relation to cope with vulnerability or stress. Besides, development infrastructure, social status, and cultural norms and values also determine who and how an individual, household, and community will be affected by climate change (Moench 2007), The social structure of Loba is divided mainly into three different socio-economic groups. They distinguish themselves with power and privilege, access to and control over resources, and the way of social integration. These groups are classified as the Kutak (Bistas), the Phalwas (the Gurung), and the Ghara (occupational groups) (Chhetri 2008, 2017; Dhungel 2002; Khattri 2019). The Kutak is a local aristocrats class, including Lo king and Ghenpas. The Kutak hold the traditional position on politics or in community-level decision making as the king and village head or Ghenpa. Phalwas belong to the middle-class in social position, but economically, they are powerful as Kutak. Demographically Phalwas are the dominant group compare to others. They are the main actors of economies, whether it is agricultural, livestock ranching, trade, or tourism, and hospitality. The Gharas include various occupational groups as Ghara (smith), Shemba (butchers), Chemba (leather worker), Nepa (leather processor), Samjuwa or Sumbra (tailor), and Emeta (musicians). The nomadic herders, Drokpas, depend upon high land pasture and do not own any specific property such as house and land, are considered as structurally inferior to Phalwas. They live in a tent around the alpine pastures, depending upon the availability of pasture for yak, sheep, and mountain Billy-goat. These sub-groups are categorized as socially lowest in the social hierarchy, and they are politically and economically weakest, consequently, the most vulnerable to climate change-related disasters. Nevertheless, each of these groups has a very crucial role in maintaining the cultural, social, and economic systems of the Loba society. The social structure in the Loba society is not the caste system in a strict sense as practiced in the Hill and Tarai region of Nepal; however, these occupational groups are excluded from various social-political, religious rights and privileges even in the Loba community. In many ways, Ghara and Drokpa cope with hardship in hierarchical relations with other high ranking Lobas, similar to the unequal relationship between higher caste Lama and Dalit in Humla, Nepal (Onta and Resurreccion 2011). The role of the occupational group and interdependency among groups has been remarkably changed in recent decades, and contributing factors are globalization, modernization, and migration.

Climate change and impacts in Lo-manthang

\section{Climate change}

Since there is no meteorological station at Lo-manthang, data recorded at Chhoser station, next to Lo-manthang, the nearest available station, are analyzed to 
understand climate change in Upper-Mustang. The average annual rainfall of Upper-Mustang from the year 2006-2015 is found to be only $20.8 \mathrm{~cm}$ and is even less than that of Jomsom, i.e., $27 \mathrm{~mm}$ per year (Pandey 2016a). The year 2009 was the driest, with only $7.4 \mathrm{~cm}$ rainfall, while 2011 was the wettest with $29.1 \mathrm{~cm}$ rainfall. The rainfall pattern was highly variable (Fig. 3) since the $\mathrm{R}^{2}$ value of the trend line represents only $5 \%$ of the plots, although there is an increasing trend in annual rainfall by $1.9 \mathrm{~mm}$ per year between 1974 and 2015 .

The minimum temperatures (annual and seasonal averages) of Upper-Mustang are increasing, although there are variable rates of change (Fig. 4). The trend line of annual average minimum temperature shows an increasing rate of 0.048 degrees Celcius per year. This trend is justified relatively better by an $\mathrm{R}^{2}$ value of $58 \%$. The summer temperature is also increasing at the rate of 0.024 degrees Celcius per year, with a relatively weaker $\mathrm{R}^{2}$ value of $18 \%$. In contrast to summer temperature, winter temperature is increasing rapidly with a rate of 0.115 degrees Celcius per year and is better justified by an $\mathrm{R}^{2}$ value of $44 \%$. The temperatures of autumn (0.026 degrees Celcius per year) and spring (0.032 degrees Celcius per year) are also increasing in Upper-Mustang, although they are weakly justified by the $\mathrm{R}^{2}$ values.

The maximum annual average temperature of Upper-Mustang is also increasing by 0.048 degrees Celcius per year (Fig. 5), while the rate of increase in summer maximum temperature is 0.055 degrees Celcius per year, and that of the winter is 0.049 degrees Celcius per year. The trend lines of spring and autumn maximum temperatures are also increasing at the rate of 0.071 and 0.008 degrees Celcius per year, respectively. Nevertheless, all of the trends poorly justify those increases as all the $\mathrm{R}^{2}$ values are weak. The analysis of temperature data indicated notably increased winter temperature, so it is supporting earlier findings i.e., faster melting of

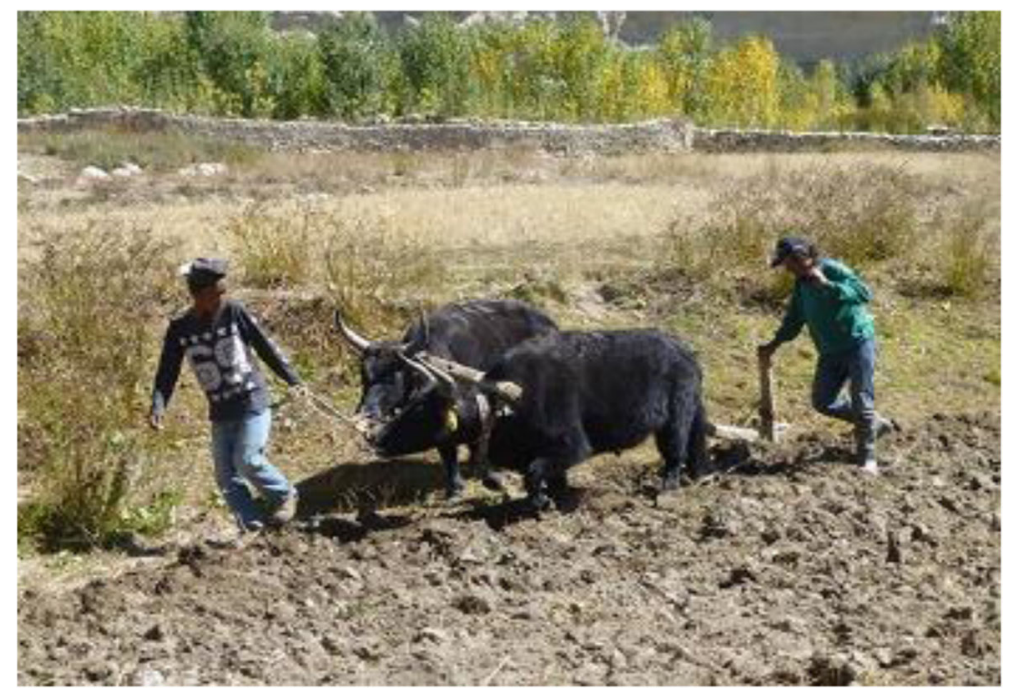

Fig. 2 Plowing in Upper Mustang, where jhopa are assisted by another person 


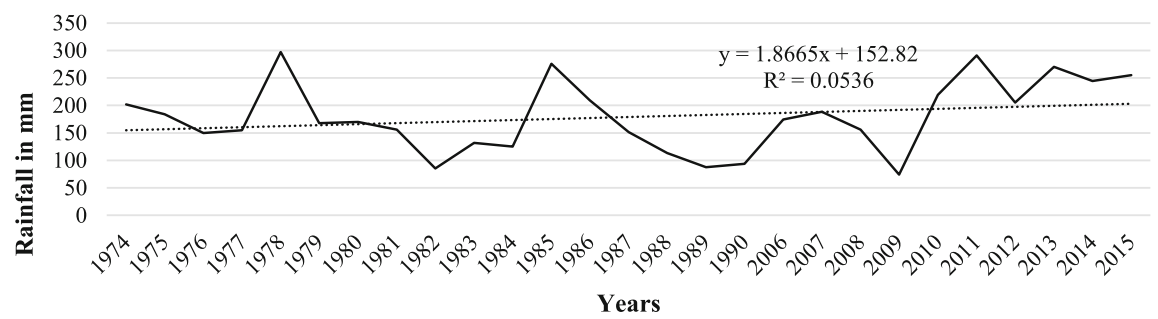

Fig. 3 Variation in Annual Precipitation in Upper-Mustang (Chhoser Meteorological Station), Nepal (Source: DHM/Govt of Nepal)

winter snow and increased runoff resulted in to reduced water storage in the region (Pandey 2019a).

\section{Climate change impacts}

Floods and landslides are becoming frequent with the increase in sudden and intense rainfall events in Nepal (Pandey 2016a). The respondents of Lo-manthang second the same finding. The flooding in the Upper-Mustang has changed the state of natural resources. Flooding has increased the accumulation of debris and silt due to accelerated soil erosion in farmland and other areas. Increased rainfall instead of snowfall on the sensitive landscape, which is unusual, leads to severe flooding. Such flooding frequently injured lives and livestock and has disrupted accessibility. Flood induced damages in houses and irrigation infrastructure, as well as a load of siltation in farmland and large-scale sedimentation in the lower reaches of rivers (Fig. 6) are commonly observed during the field visit. The management of infrastructure has become increasingly difficult and costly in Upper-Mustang. The research participants reported:

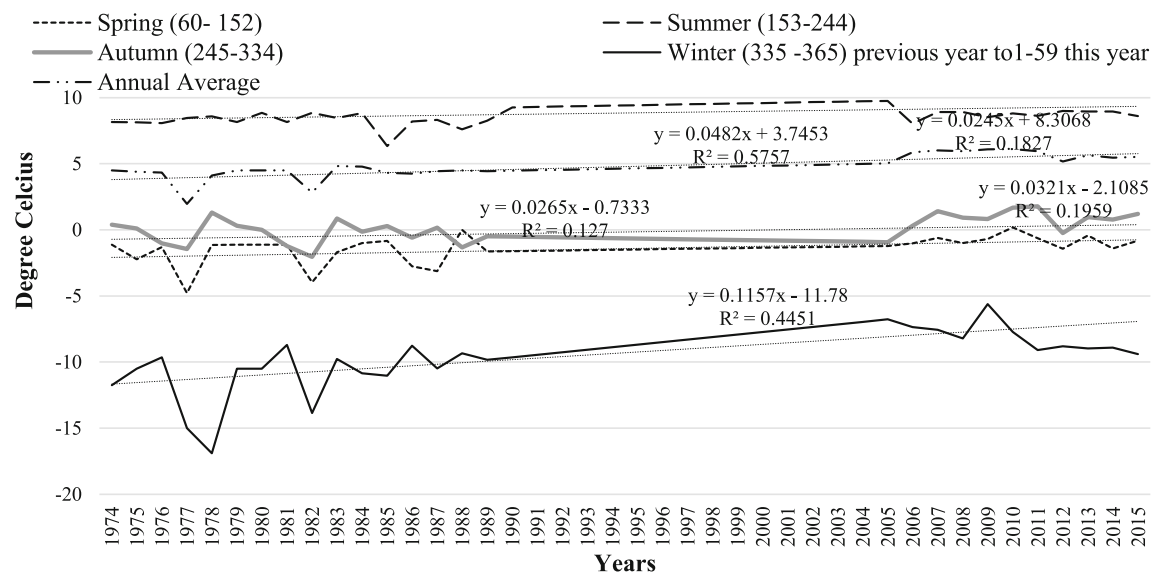

Fig. 4 Changes in Average Minimum Temperature in Upper-Mustang (Chhoser Meteorological Station), Nepal by Seasons (1974-2015), (Source: DHM/Govt of Nepal) 


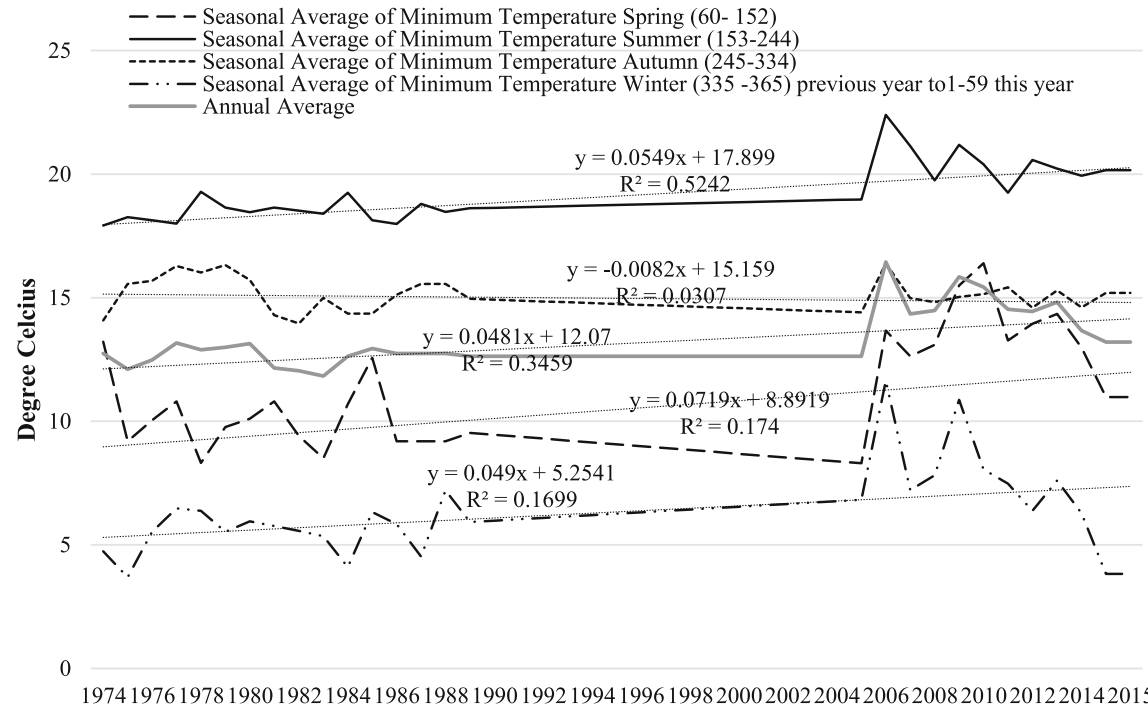

Years

Fig. 5 Changes in Average Minimum Temperature in Upper-Mustang (Chhoser Meteorological Station), Nepal by Seasons (1974-2015), (Source: DHM/Govt of Nepal)

... We have never experienced such landslides, floods, and active streams and rivers in the past like we are seeing them in recent years. ...

According to the respondents, snowfall stores water for dry periods and supplies soil-moisture for a longer period. It also controls surface runoff, so it does not encourage soil erosion and landslides like the surface runoff. However, changed in the rainy season and shift from snowing to raining (Pandey 2016a) encouraged surface runoff in the highly dynamic landscape that have caused severe soil erosion and flooding in the rainy season, and moisture has been scarce in the dry season. Besides, the snow accumulated on flat mud-roofs used to supply water for domestic use for extended periods in the past. However, the changed pattern of precipitation has increased the problem of roof leakages and damage on the walls. The households have to fetch more water from public taps on the other as well. Offseason snowfall (snowing in early spring) in recent years has damaged crops,

Fig. 6 Highly silted irrigation infrastructure in the Trans-Himalaya, Nepal

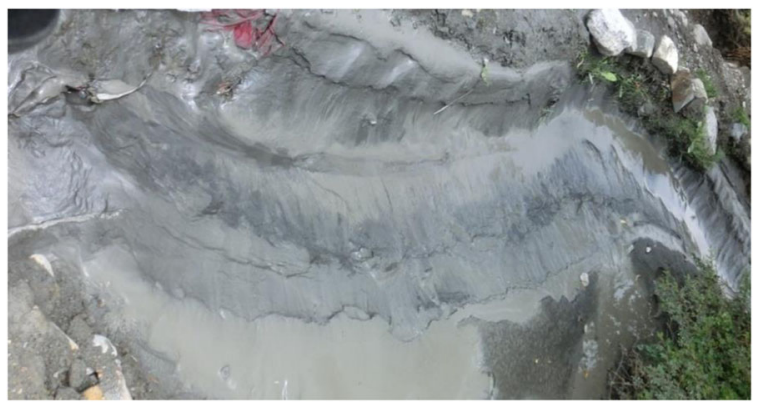


Fig. 7 Colorful agriculture field and desert type of surrounding outside field area (photo credit to Sontosh Sherchan

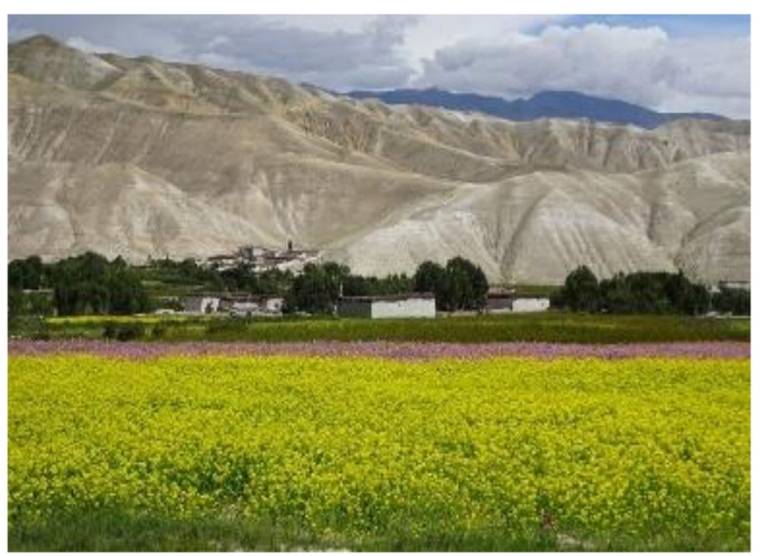

including oats, wheat, and barley. It has also encouraged crop diseases and increased insect numbers.

Furthermore, the farmers also reported that grazing animals in the high altitude pastures lack fodder, forage, drinking water, and shelter due to off-season snowfall, leading to an increased number of livestock deaths. Frequent rain-storms during the apple blooming season reduced the quality and quantity of fruits. These findings are mostly consistent with the findings from other studies conducted in the Trans-Himalaya, Nepal (NTNC/ACAP 2012; Pandey 2019a; Paudel and Andersen 2012; Sharma et al. 2009).

Many climate change impacts are secondary or tertiary, making it particularly difficult to attribute them to a changing climate, and yet are likely to become more important with climate change. For example, fire incidents in the Trans-Himalaya are increased, although it could be associated with the area's clustered settlements and the use of open-fires for heating (Pandey 2019a).

Fig. 8 Newly harvested crop offered to the local deities

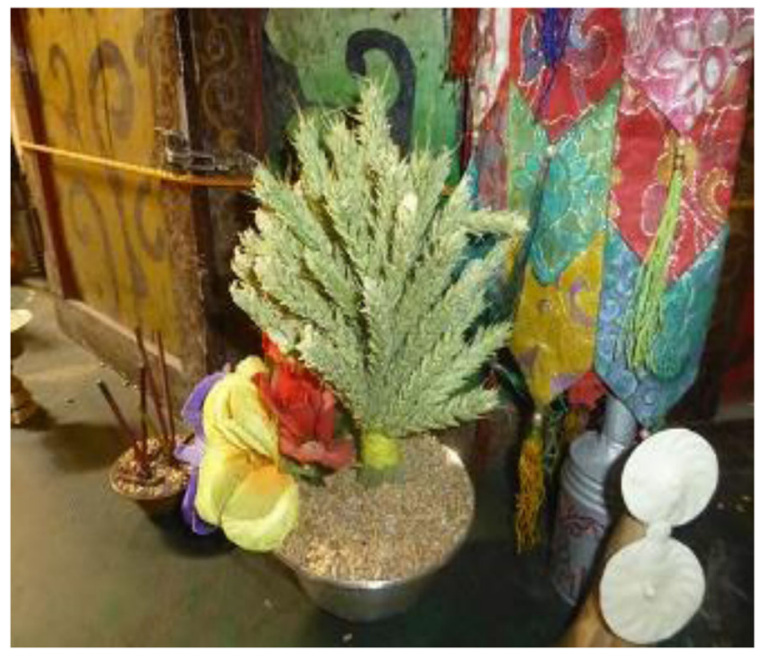


Fig. 9 Mustard harvesting

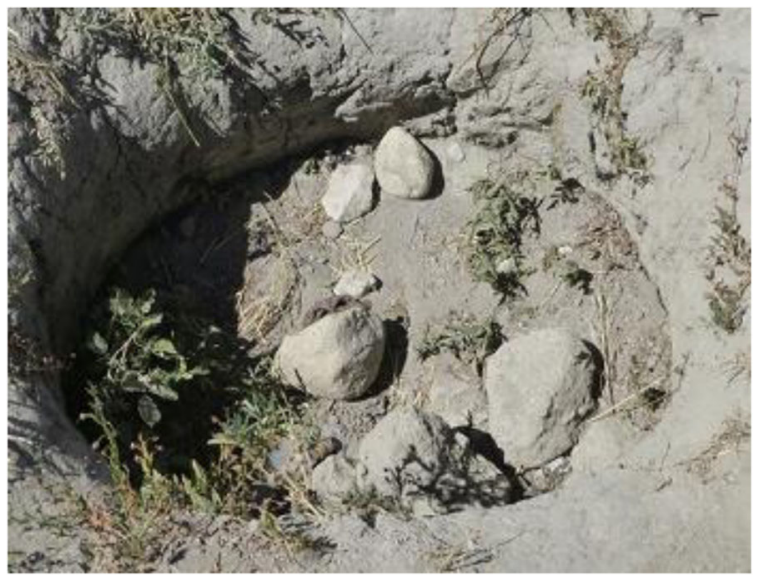

The communities of the Trans-Himalaya noticed little increase in invasive species as farmers report seeing new weeds occasionally. The people have witnessed changes in the flowering, fruiting, and ripening seasons of fruits. Research participants reported the blooming of Rhododendron some 3 weeks earlier than in 'usual' seasons in the Trans-Himalaya. Changes in flowering and fruiting seasons also been observed in peach, pear, apricot, mostly below 3500 masl, with most of the early blooming leading to unsuccessful fruiting. Farmers also reported larger size apples with a better taste in higher altitudes as warming goes. The warming has also resulted in increased crop-livestock diseases, and the emergence of new insects, which have negatively impacted on the mixed crop-livestock systems of the region. Many agro-livestock related issues are associated with the changed snowing season. The availability of water sources and widespread decrease in water shortages associated with diminished rainy days and rainfall instead of snowing are leading to early drying up or reduced flow of springs in the Trans-Himalaya, further implicating into irrigation and domestic water supply.

Fig. 10 Potato Storage in the ground

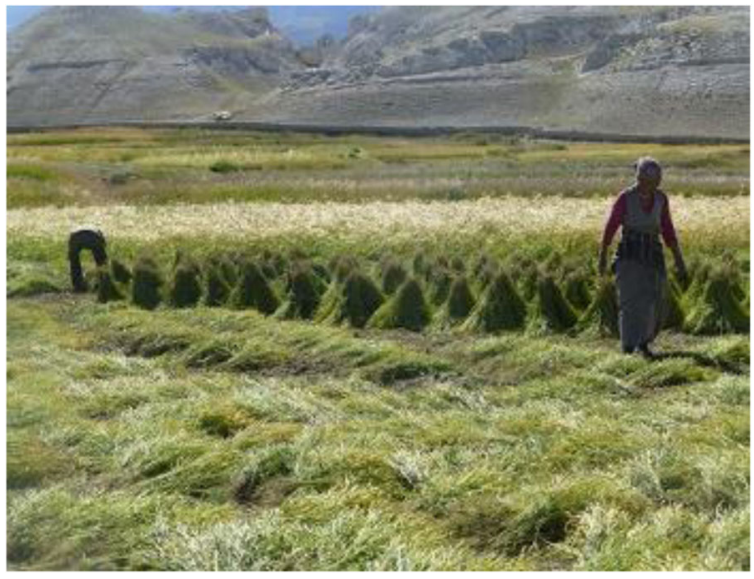


Fig. 11 Grass Hooper, the insect which attacks buckwheat increasing intensly as new phonemena

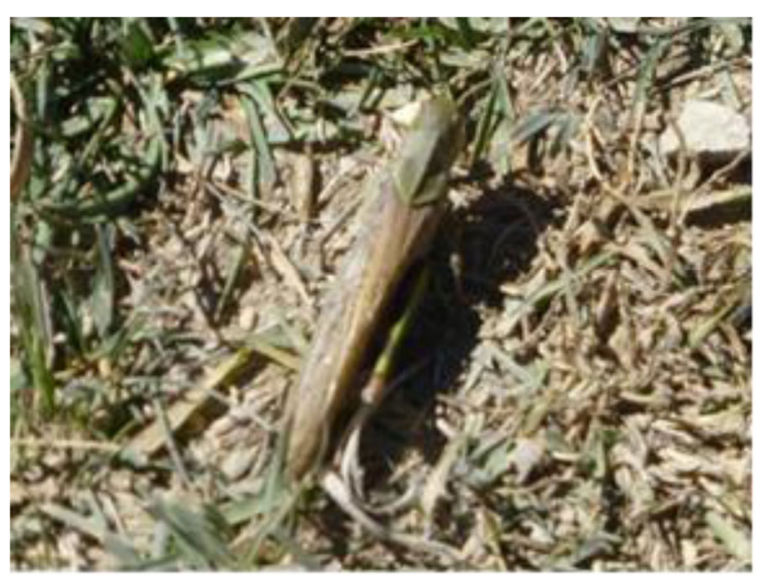

The discussion above showed some notable impacts of climate change in the social-ecological system of Upper-Mustang. Below, we present the adaptation efforts of indigenous Loba communities.

Indigenous adaptation strategies to climate and environmental changes

\section{Changing the value of food}

Food produced at the farm and from livestock has multiple values for the Loba community. Most of the meals they consume include some portion of meat. Since Lobas have been living at high altitudes (above 3700 masl), they face long and harsh winter and short and pleasant summer seasons. Therefore, Lobas need heatproducing food to maintain the physiological requirement of their body. According to Lobas, meat generates heat, which helps them to cope with a severe cold. Many Loba food items are prepared in a soup form. Besides the food they consume, they keep livestock at the ground floor of the house and live upstairs, and also use

Fig. 12 Green vegetable farming becoming a new phenomenon for diet and source of cash income

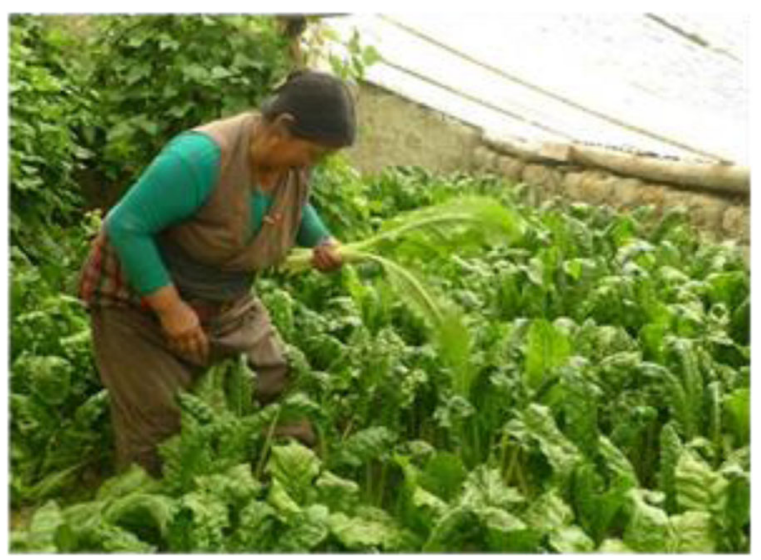


Fig. 13 Horses are used for thrashing crops traditionally

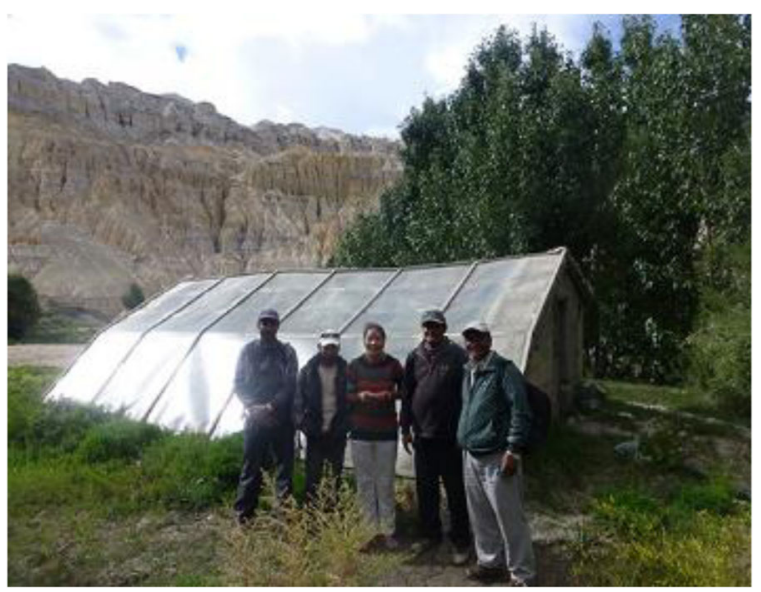

animal dung as fuel to generate heat. Food is itself a medicine (Kassam et al. 2010). The Lobas of Upper-Mustang makes their food, called tsampa made of flour from naked barely. The tsampa is considered to be medicine, so it is consumed every day together with buttered tea and chhurpi, (dried cheese), especially in the morning, before they go out for work. Tsampa is an essential food for old, sick, and young children since they are uncomfortable with hard food. These group of people consumes mush and thukpa made of tsampa. For the sick, and elderly as well as children, they add more nutritional items such as butter, sugar, and dried cheese in tsampa. In the past, tsampa was made through the flour of the naked barley ground in ghatta (traditional water mill). At present, a few modern grinding mills are available in the region. People feel that the tsampa made of flour ground at Ghatta is delicious. With the course of modernization and dependence on marketed food, Lobas have already lost food sovereignty, although they were food sovereign some 40 years ago. They are consuming various kinds of food and drinks (rice, wheat flour, sugar, salt, varieties of noodles, alcohol, juice), mostly imported from Tibet or down-stream (Myagdi, and Pokhara), or donated by the Government

Fig. 14 Green house as technological adaptation used for vegetable farming and growing seedlings

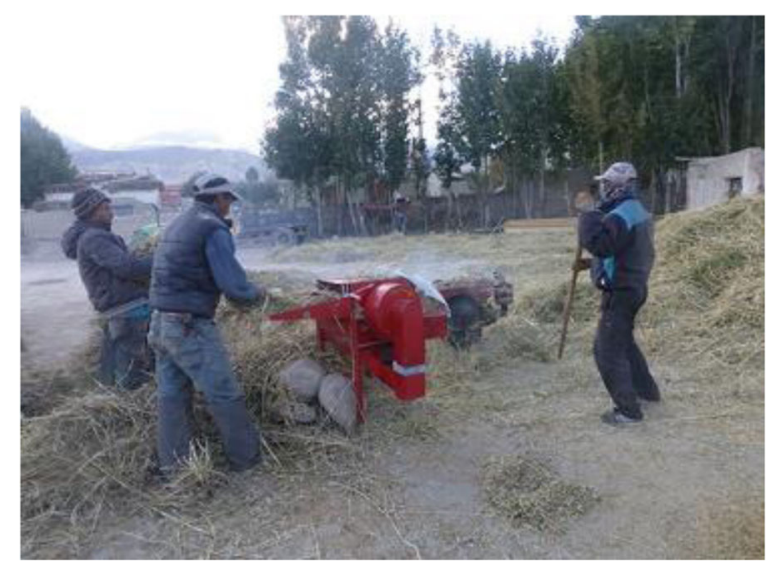


Fig. 15 Thrashing machine: A beginning of technological adaptation for labor saving and avoiding possibility of extreme weather events

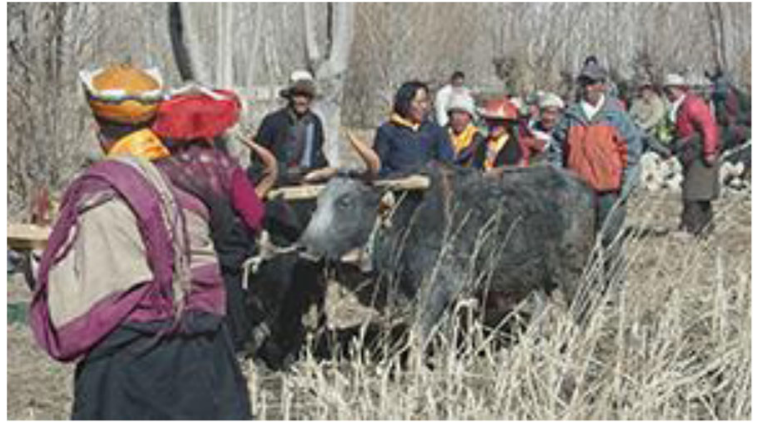

of China as well. Nevertheless, food is not only the cultural but also the means of social interaction among the Lobas.

The food production, processing, preparation, and consumption, are all social activities in Loba community. During the food cultivation, harvesting and processing time as well as while consuming the food, participation of the male and female, older people of family, children, relatives, and the neighborhood is required, with their traditionally defined roles. Usually, women are heavily involved in cultivation; however, males always support them. The agriculture season begins with the ritual, sakaluka, in which women plow the agriculture field first. This indicates women's important role in farming despite the Loba community being patriarchal. Gau Mukhiya (the village leader), in consensus with villagers, decides the date of Sakaluka and other auspicious activities to be performed in Lo-manthang. According to Amchi Gyacho Bista (58/M), "women plow the land in order to make the 'God of land' happy, so the villagers are blessed through good weather at first and good harvest later".

In the everyday agricultural activities, men plow the fields, and women prepare and preserve the seeds, harvest crops, and prepare meals for the farm workers. Loba women follow the norms of priority of eating, that is the elderly males first. The sitting arrangement next to the hearth is also socially assigned, and it is the

Fig. 16 Sakaluka ritual in Lomanthang, Photo credit Santosh Sherchan

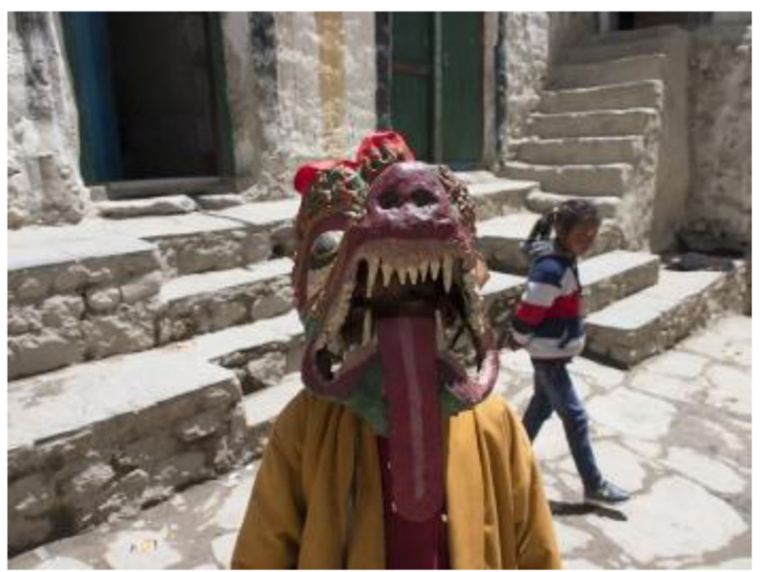


eldest person. Age and gender relations, while meal time has social meaning as it is related to respect and care. However, the relation between males and females in access to and control over the decision making over the mobility of family members and on the use of resources indicate women's superiority or higher status in the Loba community (Khattri 2019).

Lobas most practice modern cash-transection economy. Grains and livestock are exchanged for cash, goods, and services. The amount of grain produced, landholding size of household, and the number of livestock owned, determine their social and economic position. It also implies to household's food sovereignty and food security status. The food produced in Lo-manthang used to be bartered with Tibetan salt before the 1960s and while Himalayan medicine and spices used to be bartered to grains with the people of southern hills in Nepal. There used to grain trade to Tibet in the past called salt and grain circuits, where mules, horses, and donkeys used to be the means of transportation, particularly during the spring and summer seasons (Fig. 7). With the course of modernization and Tibet being food sovereign area, Upper-mustang, including Lo-manthang, lost food sovereignty and trade-hegemony in salt-grain circuits.

A few decades earlier, there used to be adequate availability of water and more predictable weather conditions, so the households used to be able to keep many livestock. Such a livelihood option used to be facilitative to the adaptation to the harsh environmental condition of the region. Nevertheless, locally produced food is consumed hardly, only during the ritual ceremonies, if there was an excess amount of grain after making ritual offerings (Fig. 8) like torma to the ancestors and other deities in these days. The food gain they produce is offered to the divine powers before they are consumed. The marketed food has become the staple one in these days in Lo-manthang.

Food from livestock is also a crucial part of the social, economic, cultural, and religious aspects of the Loba community. The Lobas milk cows, sheep, goats, and yaks, and produce butter and churpi (dried cheese). Butter from sheep and goats is used to make Tibetan tea. Yak meat is considered a delicacy for marriage and other public feasts. High-class Lobas highly praise these items. To manage herds, and supply food for winter, they slaughter sheep and goats in November/December and stored the carcass by hanging openly on a nail on primary wooden-pillar in the house. The items they produce from livestock have specialized meaning, such as respect and blessing, and are precious during the rituals to offer to God. It is placed on the forehead at the time of farewell to the traveler (family members and relatives) with the wish of a safe, happy, and successful journey. It is also used to ward off the evil spirit by placing it on the top of the door (at upper-norm) of the house. Lobas serve butter on a cup when they serve tsampa, and salted (Tibetan) butter tea for guests and relatives as an honor. Butter, milk, and meat are used for medicinal purposes as well. All these practices indicate the importance of keeping environmentally adaptive livestock for household food security, maintaining identities, and preserving social-economic power in the Trans-Himalaya and Loba community.

Food in the Loba community has a specialized meaning of power relations that feast is organized each year on the occasion of Loshar (New Year) and Yartung 
(horse riding competition). These feasts allow economically well-off households to win the favor of people. Members of each household participate in those feasts. Liquor from naked barley is served and consumed by household members and while making essential community decisions. The village head offers locally made liquor to the local king, to inform about the beginning of cultivation or harvest season. As meat becomes a part of the feast together with other food items, livestock plays a crucial role in exchanging power dynamics in the community. Social and political power is expressed through consuming exotic food items.

Although the rice is not produced in Upper-Mustang but bought at down-hill Beni or Jomsom, the Lobas have introduced it as a new food item and consuming it is considered as the social and economic prestige. The Lobas sometimes receive subsidized food-grain such as rice, wheat flour, and other items from the Government of Nepal; nevertheless, due to high transportation costs from Beni or Jomsom to the south, freely given rice becomes quite expensive while reaching to Lomathang (Pandey 2017). Despite the risk of quality of rice being degraded due to improper packaging and storage while transporting from a distant market center, people prefer to consume rice as an exotic food item of high class. This trend is gradually threatening to local production and consumption systems of wheat and naked barley on the one hand and people losing food sovereignty due to higher dependency on marketed food on the other. The higher share of marketed food being consumed has also increased the importance of cash income in the region.

\section{Crop diversification}

Crop production is not only associated with consumption, distribution, or exchange of food but also a medium of maintaining social relations and means of social interaction. Crop cultivation is primarily dependent on land productivity that includes but not limited to soil, water or moisture, and suitable local environmental conditions. The crops also bear special social and community meanings. Considering those elements, Lobas of Lo-manthang carefully chooses certain crops as the main. The Lobas have categorized the crops as kar or white (wheat and naked barley) and nak or black (mustard, peas, buckwheat). The nak crops are characterized by short growing season and can be cultivated in less fertile soils, while kar requires relatively better soil and longer growing season. The major crops produced in Lo-manthang are wheat, buckwheat, naked barley, peas, mustard, and potatoes. The Loba cultivates alternative types of crops on a rotational basis to maintain soil productivity.

The production of peas, buckwheat, and potatoes is increasing in UpperMustang since they are on high demand from Pokhara and Kathmandu. The products of Mustang are becoming souvenir items for both domestic and foreign visitors. Buckwheat is economically beneficial as it is getting a better price in recent years. Ojha (1982) has documented the price of buckwheat as one pathi (c.2.77 kg) cost 250 (\$2.5) and one-kilogram buckwheat flour cost 250 (\$2.5) in the local market during the 1980s. At present, the same amount of buckwheat cost NRs 525 (\$ 4.64), and the same amount of buckwheat flour cost NRs 700 (\$ 6.19) at Lomanthang. Buckwheat flour in Kathmandu cost NRs 200 (\$ 1.76) per K.G. 
The staple food of Lobas, the tsampa, most nutrient food, is made flour of naked barley. Potatoes and turnip are also grown in a significant amount in Lomanthang, and they are famous for their special flavor and produced in the organic environment of the high altitude farms. The Lobas store potatoes digging a yawning pit (see Fig. 9). The Lobas and the tourists enjoy food items of fine-grained wheat flour bought from the market. Wheat needs more irrigation (at least 6-7 times) than other crops grown in Lo-manthang and thrashing it is also labor demanding, although thrashing machines (see Fig. 15) are being used by some households in recent years, are causing poor preference. In recent years, rice is available at the same price as to local wheat despite the fact that it is imported. Local wheat has been becoming a less valuable crop. The negligence of wheat and people's shift to rice from wheat and increased consumption of junk food to locally grown and processed food resulted to loss of food sovereignty in Upper-Mustang (Pandey 2016c).

Naked barley is the most important crop to make staple food Tsampa. Loba women consider making Tsampa as a tedious job. Firstly, naked barley is washed with water; then it is sun-dried and then fried (steamed) until they are warm but not fully dried. Then they keep on a sack to clean pressing with hands and feet. It needs winnowing the dust and brought to the mill to grind in fine quality. The naked barley used to cost NPR 300 (\$3.25) per pathi (approximately $4 \mathrm{~kg}$ ) in Lomanthang in 2014. People of Upper-Mustang also produce mustard for cooking oil and to lit oil-lamps, which can also be offered to their deities (see Fig. 10).

Drokpas, who used to buy surplus grains from Lo-manthang in the past, has started to trade rice, indicating the change in food consumption and trading. The situation also informs that the priority for local food is decreasing, which is raising the issue of food sovereignty and consumers' control over the price of marketed foods. The local distribution system of food has also changed due to the presence of new food items. People have changed their food habits, and the consequences are that the economic or monetary values of crops and livestock declined.

The Lobas consume some local food items, which are cooked simply - steaming, boiling, frying, and roasting. Lobas' food is easy to make, yet contain full of natural goodness (NTNC 2011, 13). The butter-salt tea (chhyaby jha), Tora Khuwa (juice), Mustang coffee, tsampa, buckwheat pancake, wheat roti (bread), fried potato, garlic soup, vegetable and varieties of meat, and mo:mo: (Dumplin) are the traditional well-known food items of Loba people. However, new items such as rice, noodles, and even other fast-food items have already been introduced with the course of advancement in tourism, and local people also give priority to new food items. There is a bakery in Lo-manthang, which was recently established.

During the 1980s, wheat and peas were the major crops in the region. Pea was a popular crop item produced as feed when Lobas used to keep a large number of horses, mules, and donkeys. However, as the size of herds has been declined sharply, and it is not such a popular item to sell out, the production of pea has declined in the study area. Furthermore, the introduction of new crop items also has an effect that Lobas cultivate varieties of crops, which are interlinked to their social, cultural, and economic as well as nutritional and medicinal dimensions, and are adapted to the local but dynamic ecological system of Upper-Mustang. Lobas have become more selective in crop 
cultivation recently. The forces behind better crop-diversification are the changed value of crop varies, in terms of both market price and people's preference for consumption, and dynamics in livestock ranching, and their use as as draught power. The traditional means of transportation, i.e., draught power is replaced by motor vehicles in the region, and Drokpas also use motorbikes for their mobility. The use of motorbikes and motor vehicles have reduced the scope and skill of driving herds of livestock, causing a severe decline in the herd size (Pandey 2016b; Yeh et al. 2014).

The productivity of crops in Lo-manthang depends on the region's weather condition (period of frost/snowing and occurrence of hails) and the level of the outbreak of pests and insects (see Fig. 11). The climate change has challenged traditional indigenous knowledge of agricultural practices and understanding of weather patterns that are making agricultural strategies fail (Manandhar et al. 2011; Pandey 2016b). Such a phenomenon has challenged the food and livelihood security of the people, consistent with other findings such as Pandey and Bardsley (2019). There are several rivers and rivulets, the tributaries of Kaligandaki River Chhoser Khola, Karak Khola, and Chhorok drokpo, which provide water for irrigation in Lo-manthang. These rivers and rivulets generate water for 5 main irrigation canals of Lo-manthang. The irrigation canals to name are Hui, Dhurang, Suru, Kekikang, and Nigju. For drinking water, Lobas depend on Karak drokpo, which is located about $5 \mathrm{~km}$ away from Lo-manthang. However, as stated earlier, managing irrigation infrastructure and farmlands due to landslides and high siltation has become ever-challenging in Upper-Mustang.

The productivity of crops is one of the main issues in climate change research and is vital in the Trans-Himalaya because of the region's low productivity in relation to farm inputs. Poor quality of soil for farming, inadequate manure and water, cold temperature, and extreme weather events, together with the high cost of farm management, have made cultivation unprofitable. Sometimes, the production becomes lower than the seeds been broadcasted since the seeds have to be sown at high concentrations as a response to a low-temperature low germination rate. Other reasons are the birds, rats, and other insects, which damage seeds before they are germinated. Since thick broadcasting of seed is required, around $21 \%$ of the grain harvested in Upper-Mustang is saved for seed (Ojha 1986). Literature also reported severely low productivity of food crops in the region as the yields range from 1:3 to 1:6 (Chhetri 2006). Yearly crop rotation of kar-nak model is a well-established practice that is said to enhance soil fertility and avoid insect invasion.

In the past, the Lobas collected grass, peas, mustard almost simultaneously, for which new customary law has been developed in recent years that people harvest grass first, followed by crops accordingly to their preferences. After harvesting the crops, they allow animals to graze in their fields. Grazing practice has two purposes - first, the herds fertilize the land while grazing, and they eat herbs, which requires weeding unless the livestock grazing. Harvesting either grass or crops first have ecological and economic meanings that there are no farmland abandonment in the past. However, it is increasing recently. Also, there was enough pasture in the past to the high altitude, and to the pastures of Tibet. At the same time, crops and livestock were much valued because they were using for trade to Tibet. However, at present, the value of local crops in Lo-manthang has changed, specifically 
declined, in comparison to the past, and modern transportation and increased access to imported goods is to blame. Additionally, Tibet has also been stopped buying food from Trans-Himalaya as food supplied from China's mainland side is far cheaper because of a better transportation network. Nevertheless, the Lobas are continuing agricultural practice as their traditional occupational identity, to hold land as their ancestral property, and also due to their partial dependence on the local social-ecological system for their livelihoods.

\section{Vegetable and fruit farming}

There is a good probability of growing varieties of vegetables (Fig. 12) and fruits in Lo-manthang. The temperature of the region is rising, so the farmers are obviously adapting new technologies (Fig. 13 \& 14), so fruits and vegetable production is positively impacted. With the increase in the production of new varieties, people have started to consume vegetables and fruits domestically, and they also make some cash income from surplus production. Lal Prasad Gautam (M/41), a staff of the Annapurna Conservation Area Project (ACAP), shared his 14 years' experience of working in Upper-Mustang as:

In the past, people did not have the habits of consuming green and leafy vegetables, except seasonal potatoes, thulu radish, and buckwheat, so they did not cultivate vegetables. The ACAP tried to grow vegetables in 1994-95 for the first time at Marpha, a southern village of Mustang. Later on, it is found that varieties of green vegetables, including asparagus, are well adapted to the soil and temperature of Lo-manthang. As that production of vegetables adds recipe in the Hotels of Lo-manthang, a variety of vegetables started to be grown, at the altitude of 3750 masl. They grow seedlings inside the greenhouse and transplant them to their kitchen garden. Since 2005, the ACAP has started to facilitate communities to grow several types of vegetables, such as zucchini, cauliflower, cabbage, carrots, coriander, string bean, Windsor bean, turnip in Upper-Mustang. It is identified that zucchini used to be grown only inside the greenhouse until 2009; however, by now, they are adapted to the outdoor environment as well. The bitter gourd is also started to grow outside of the greenhouse at relatively lower parts of Upper-Mustang, such as Chhuksang, Surkhang, and Dhin villages. The cucumber is successfully grown in the outside environment at Tanbe village. At present, tomatoes are grown inside the green-house in Lo-manthang, Chhoser, and Chonhup, and it is expected that it might be possible to grow in the outdoor environment soon. The main difference in cultivating vegetables in Lo-manthang than in lower elevation is that the varieties which are grown during the winter in the lower hills are cultivated here during the summer season. The Lobas were able to grow snow mystic cauliflower, single weighing up to $4.5 \mathrm{~kg}$, in Lo-manthang. To grow onion in the area, it used to take up to two years until 2009, which is growing within a year and in the outdoor environment in recent days. Furthermore, there was no apple in Ghami village, and whatever produced there were used to be sour. Now, they are better tasted now, and people are establishing apple orchards high 
above. Apple, peach, apricot, plum, pear, grapes, walnuts are being cultivated in Upper-Mustang and in and around Lo-manthang. Farmers had been able to earn up to NPR 70,000 by selling their vegetable product of a particular year, i.e., 2015. Hotel owners also produce some vegetables themselves, and some farmers in Chhoser also earned up to NPR 50,000 NPR annually by selling vegetables. A few farmers of Lo-manthang own greenhouse, they have been trained to grow seedlings so they and earn up to NPR 30,000 annually by selling the seedlings of cabbage, NPR 17,000-18,000 by selling the seedling of cauliflower, and NPR 10,000 by selling the seedling of broccoli. The ACAP has distributed about 12 KG seeds of mustard in Lo-Manthang, Upper Mustang. Nowadays, seedlings of cabbage and cauliflower are prepared at the outside environment. Maize is grown in Thinger village, while people also started to cultivate hybrid wheat such as RR 21. The height of the straw/plant of this variety of wheat has observed to be short there and takes short growing season as well. Therefore, it ripes earlier, with better yields than the local variety. As the variety is a fast growing, adapted to the local environmental conditions, and is not affected much by the strong winds of the region, farmers have preferred to cultivate hybrid wheat.

Although climate change has extended the growing season of Upper-Mustang and varieties of crops, vegetables, and fruits, started to be grown, an increase in invasive species (farm weeds and insects) are growing. Weeding the farm's increases crop-productivity, so it is done several times, up to 6 times in a single cropping season in Lo-manthang, depending upon the availability of labor and the level of weeds grown in a farm-plot. Weeding is mainly done by women. The Lobas have started using the hand-gloves in order to protect their hands while working in the field. The buckwheat has been the vulnerable crop to a grasshopper, and khumre kira (grubs), the earlier destroys the green plants while the latter damages the plant by eating the roots of plants, creating new challenges. People have been practicing organic farming, and due to the area's climatic condition, the region is vulnerable to the use of pesticides. The people are using organic pesticides to control the pest. As found by earlier research such as Pandey (2016c), warming in Upper-Mustang is not only experienced by the people of the region but also been observed in the natural ecological system that the barren Trans-Himalaya is becoming ever greener.

\section{Labor management - the Lakti Chikula practice}

Agriculture demands much works, for maintenance of irrigation infrastructure, carrying animal dung to the farm-plots, and preparing the fields (plowing, digging), sowing seeds, weeding periodically, harvesting the crops, carrying the harvest to the home, thrashing the products, storing, sun-drying and grinding or husking. There are some specialized roles such as seed broadcasting, which is done by the well-experienced person while general works are done by everyone, including young children, as young as 12 years of age. Hired laborers, along with available adult members of the households, also contribute in general works. The wage-rates of the laborer are increasing faster (laborers reported that they earn NPR 400 to 500 in addition to three meals a day - 
breakfast, lunch, and evening meal), and farm output is becoming unprofitable., The working hours are $8 \mathrm{AM}$ to $6 \mathrm{PM}(10 \mathrm{~h})$ a day for a paid laborer. Due to a shortage of labor, the Lobas hire laborers from Baglung and Rolpa districts, particularly during the harvesting periods. Several persons from Baglung and Rolpa districts visit Lomanthang for seasonal work in the construction and driving sectors. They also accompanied their dependents, who work as agricultural laborers during the farming season.

The labor shortage in the Loba community is managed through a traditional method named Lakti Chikula. It is a form of rotational mobility of farm laborers from one household to another, even one area to another turn by turn, and the turn is arranged by the Zho (the owner of the labor group). In the case of moving across the areas, they work at the lower altitude farms first and then to high altitude farms. The Lobas of Lo-manthang, however, cannot practice this form of labor exchange during the harvest season, mainly due to the fact that the harvest should be completed in quite a short duration, and every household have to harvest their products at the same time. There are only two pairs of Zhos in Lo-manthang, which is not adequate to perform all the farm-activities in a short period, they hire more zhos from different neighboring villages such as Fuwa, Kimiling, Thinger, Namgyel, Dhakmar, Ghami, and Surkhang. The inadequacy of farm labor is substituted by the adoption of machineries in agriculture. In the past, harvested crops used to be thrashed by horses and sticks with ropes tied in it. However, the practice is replaced by a thrashing machine these days. The households who do not afford to buy or hire a thrashing machine, still use horses and sticks. Similarly, a plowing machine is also been introduced in Lomanthang. One of the key informants from Loba community expressed his interest of buying a plow machine in Kathmandu and take it to Lo-manthang. He said that it is hard to keep Jhopa (the bull to pull wooden plow), and if the farmers do not own Jhopa themselves, it is hard to hire them for the short sowing season. Many farmers have expressed similar problems, so the machine plow might meet their needs since its capacity of plowing farm lots in a day would be sharply higher than that of the draught power (Jhopa). A single machine can be hired by many farmers as its performance would several times more than the normal plow.

\section{Collective Management of Irrigation System}

Collective maintenance of irrigation systems is a common practice at Lomanthang. The system includes, but is not limited to the construction of reservoirs, channeling the ice-melted water, repairing the damage of extreme weather events and Glacial Lake Outburst Floods (GLOF), controlling water pollution, and ensuring access to all farmer and proper utilization of water for domestic, livestock, and farm use. The entitlement of the use of irrigation water at individual households or farm-owner is difficult, so its collective management is obvious. Irrigation canals supply water from nearby streams such as Dhokpo Lho, Dhokpa Zhang, which are the glacier feed streams. There are different canals to supply irrigation water in Lomanthang: Huyu, Suruk, Samzi, Kya-kya Ghang, Dhurang, and Ghayaga. When canals are damaged at the level beyond the repairable capacity of villages or the users, the option remains to abandon the field at first and the village later. One can easily observe the abandoned fields in different places in Upper-Mustang, 
including in Lo-manthang area. Much of the abandonment has been reported to be for the last 30-35 years. The agriculture and farmland abandonment in Lomanthang has been affected not only due to global warming and associated extreme weather events but also by tourism and infrastructure development activities, however.

The local community is the main stakeholder for the maintenance and protection of canals adapted by (Chhetri 2008), which are governed by the traditional rules. The users have also developed a local system of distributing water at the head-end and tail-end in the level/sloping terraces. In recent years, the community people are getting support, in kinds, such as cement, gabion wire, and polyethylene pipes, to repair the channels from different Non-governmental Organizations and local governments. As the Upper-Mustang/Trans-Himalaya is a dry-land, not only the farmland but also the plantation area and orchards need irrigation. Loba have planted trees at the edge of the canal and farmland that maintains greenery in the area. Such trees also reduce soil erosion on the one hand and control debris to the canal and farm. According to a key informant, every year, people have abandoned a part of previously cultivated land, which is being developed as a grazing field or a fodder field. Consequently, the total grain production in Upper-Mustang, including in Lo-manthang, is decreasing.

Crop cultivation requires regular irrigation, and it is crucial in climatically dry land having the permeable soil structure with high infiltration (Pandey 2019a) and evaporation rates due to intense sunshine (Ojha 1986). In such a context, the Lobas have developed a specialized schedule of irrigation and are known through different Loba terms (see Table 1). Since water is not available sufficiently and irrigation canals are damaged frequently, arrangement for regular maintenance is obvious. In order to solve that problem, Lobas have developed a village head system, who mobilizes obligatory labor contribution from the users. The entitlement to irrigation water is lost if a landowner did not cultivate the land in a particular year, and such practice reduces the tenure exchange of farmland, leading to an abandonment of farmland in the Trans-Himalaya (Pandey 2016b). Although village heads take most of the responsibilities, he is assisted by Midhi, and Chhyumes. The Ghenpa is elected annually from Kuthak households and in a rotational basis. The village functionaries have the right to fine the defaulters, called Chhipa in Loba term. The defaults could be any, farm-related such as irrigation or crop damaged by livestock or social offenses and misconducts. Labor contribution for maintaining an irrigation canal is fixed proportionately, based on the size of landholding (the amount of seed required for the land). The local unit of land measurement is khal, equals to 170 $\mathrm{m}^{2}$.

The community determines the Khal. In the past, a well-experienced person was asked to saw seed on everyone's land, and the required seed for the specific area was recorded, which is also used to determine the number of labor-day(s) contribution required to provide by a household to repair canal(s) every year. Those houses that do not own farmland but are residing in Lo-manthang also have to contribute a day of labor because they also use water for domestic purposes. Hence, the irrigation system in Lo-manthang operated with 'culturally embedded knowledge' (Chhetri 2008). At the time of field visit for this study, there were 12 irrigation 
Table 1 Name and schedule of irrigation in Lo-mathang

\begin{tabular}{lll}
\hline SN & Local Names & Meaning of scheduled of irrigation \\
\hline 1 & Tapchu & Before seed broadcasting \\
2 & Nyogu & When shoots are seen \\
3 & Rechchu & One and a half feet tall \\
4 & Bhachchu & During flouring time \\
5 & Majyu & During flouring time \\
6 & Mikchu & Seed bearing time \\
7 & Najiu & Before harvest \\
\hline
\end{tabular}

canals in operation in Lo-manthang; among them, six were maintained and used by all the residents while the other six were used only by a few ( 5 to 20 households), since they are small canals.

\section{Agriculture and spirituality - the Sakaluka ritual}

The Sakaluka ritual (Fig. 15) is the most important one and is a collective action of the community and is a part of adaptation to the harsh climatic conditions of the region through collective spiritual practice. The ritual is performed with the wish for better climatic and environmental conditions throughout the growing season and good harvest in turn.

Sakaluka has social, spiritual, and materialistic meanings. Amchi Ghaycho of Lo-manthang says the etymological meaning of sakaluka in Loba language: "Sa means soil and manure, $k a$ means mouth $l u$ means serpent (Fig. 16), $k a$ means mouth". Therefore, sakaluka means, opening the mouth of soil and manure, and worshipping the snake (serpent, the protector of crops and managers of good weather pattern suitable for crops and animals). This ritual is performed from the 5 th to the 15th day of the first month of the Tibetan lunar calendar. The date is fixed by Amchi, observing the weather conditions. The beginning of Sakaluka informs the start of various activities such as plantation/sowing time, so the ritual symbolizes that the earth/ground is warming (ovulating). Ritual also facilitates the local way the earth be respected and treated. It also demonstrates the community's socializing the complete process of crop cultivation. Women are considered as the symbol of fertility, so women plow the land first.

The Loba people extend different rituals to seasons to maintain ecological relationships and connect lands, settlements, and houses to their spirituality and believes. The Lobas believe that the serpents become active during the Sakaluka ritual, so they are offered incenses, foods, and drinks. On the first day of Sakaluka, Lobas select a girl and a boy from the community on the basis of their astrologically matching of five elements (air, water, fire, soil, sky) at the birth year and the year of celebration. It is believed that such matching positively influences the fertility of land and productivity of crops and livestock, as well as brings fortune to human beings. Those boys and girls are known as Lopsanpa. Other criteria to select 
the Lopsanpa are that both parents should be alive, and if possible, both boys and girls are unmarried. On the second day of the Sakaluka, Lobas worship Jholah, the village deity, which is placed just above the main entrance of Lo-manthang. On the third day, they go to Chhipra, the stable of King, to take manure. The Lopsanpa boy digs manure, and the girl fills-up the basket with manure and carries it to the Ujha Chhaybu, the field of King, with a possession. In the past, there was a tradition of playing drums and singing gharloo songs on occasion.

Lobas prepare special items of food for Sakaluka, which is a delicious tsampa of naked barley mixing with sugarcane blocks, sugar, butter, and dried cheese (churpe). It is offered to serpent at first to make them happy before the community people have it. At the occasion, Lobas dig small area of farm plot and mix two manas Uwa (about a kilo) of naked barley seeds with soil and broadcast it in a small field with a high concentration of seeds. Thereafter, the girl starts plowing the field; later, the boy takes the turn. During this occasion, Lobas also worship ancestors. They change lungta, a five-colored flag placed by Boudhist in front of or at the top of the house. A similar practice is also adopted in Manage Valley as Manangi people express their collective identity (Aase et al. 2010). Similar practices are also found among the Buddhists Sherpas of Nepal who believe that recent climatic and environmental hazards are taking place because of disrespect to the snake God, $L u$, a female serpent, that is the spirit of water and land (Sherpa 2014). According to the Buddhist Sherpas, the non-Sherpas and the foreigners pollute sacred sites while diminished religious faith and behavior further contributed to weather-related miseries (Sherpa 2014, 157). Although the name of the festival and nature of worship is different, Gurungs of Lumle (South of Annapurna) also believe the same, so they worship Surya-Bahara for better weather patterns (Pandey 2019b). In Sakaluka, villagers of Lo-manthang appoint their head and his assistants, which is also to be supported by the Lama, Amchi, King, and other respected members of the community. At the same occasion, new team/authority thank the previous one and takes the oath for their tenure. The day is also the day since when the sowing season starts. If any rules are to be modified or new are to be endorsed in community, that will be done on the same day in Lo-manthang.

Lama Nowang Kunga Bista said that the worshiping snake is a part of Loba culture and is meant to prevent environmental disasters. The young generations and outsiders do not respect the spirit of the land and its spiritual linkages. They instead employ dozer and other vibrating heavy equipment that causes disturbances in the earth surface, also disbalance the peace, happiness, harmony, and prosperity of the family of mother earth. In turn, we experience various disasters. The traditional cultural practice of Lobas requires worship of land before it could be dung for any purpose, such as making homestead, road, or other structure. This ritual is only a process of kindly requesting the serpent god of the land to leave the place elsewhere so humans could use it for other purposes. The Lobas also worship the old house before demolishing it since the house has a spiritual connection.

During the sakaluka the Chang (home-made non-fermented liquor) is prepared under the leadership of old Ghempa, the village head, and offered to the participants. A mountain Billy-goat is freed as an offer to the deity, and it will not be killed for meat in the future as well. The Sakaluka ritual is performed at the 
community level at first, and the village heag would be the organizer, followed by individual households. Every household work independently to sow seeds of different varieties. Ghempas, the village heads, are obliged to decide the date of the beginning of the grass and fodder collection seasons and fixing the day to start harvesting in the eastern Himalaya - Walangchung Gola of Nepal as well (Uprety 2005).

\section{Migration}

Seasonal migration to and from Lo-manthang demonstrates a multi-dimensionality of human mobility as it involves religious, economic, and social purposes at a time. Migration has a significant impact on agricultural production and food consumption, as well as in food security. Lobas migrate during the winter, after harvesting crops. Some Lobas sell (hawkers, mobile traders termed as rigura in Loba language) local craft-items and herbal medicines. They also visit relatives, pay pilgrimage to religious sites, treat sick family members and relatives. During the migration, they mobilize resources such as cash, kinds, and humans, in relatives, kinships, and in the neighborhood. By being absent at home, they save food at home while earning cash by trading goods and services on the travel; they contribute resources to buy marketed food and other necessities. Such migration is also supporting them to maintain their cultural system, assisting themselves to cope with harsh winter, and preserving/storing and also collecting additional food and cash items, for other seasons.

The polyandry system of marriage that Lobas are practicing is changing rapidly. Such change is severely implicating into resource mobilization, especially in cultivation and livestock ranching. The Lobas are somehow coping with resources lacking, as they are getting various employment options in nearby markets centers such as Baglung, Myagdi, Kusma, and Pokhara with the course of modernization.

\section{Conclusions}

The social-ecological and livelihood systems of Loba community of Lo-manthang has been narrated extensively concerning the changing climate and their efforts for adaptation to the change. The annual average temperature of Upper-Mustang is moderately increasing at the rate of 0.048 degrees Celcius per year, and rainfall is an increase in the rate of $1.9 \mathrm{~mm}$ per year between 1974 to 2015 . The change in the climate system of the Trans-Himalaya has remarkably implicated the local socialecological system. At first, Lobas lost their sovereignty over salt and grain trade to Tibet with the rapid expansion of modern transportation in the north of China's Tibet, while the link of Lo-manthang towards the south is still unreliable. The closer of trade to Tibet has also greatly reduced the economic strength of Loba community. In such circumstances, global climate change has brought both opportunities and challenges to agriculture and the food sovereignty of Lobas. The social relationships and interactions with trans-Himalayan trade, cross-national and community marriage, as well as the use of trans-border pastures, those have been developed since ages, are facing the challenges for 
existence Consequences. Lobas have reduced herd size remarkably, they are prioritizing foreign crops or products over local production. Such changes have increased the dependency of Himalayan people to a distant part of the country or neighbor. Due to global climate change, the scarcity of water is rising, weather-related disasters are on raise, and land abandonment is increasing rapidly. In order to cope with the socio-economic and environmental constraints, shocks, and stresses, Lobas are adopting alternatives livelihood options such as winter seasonal migration, apart from agricultural adaptation efforts discussed above. They have focused on agricultural production and tree plantation, together with extending the employments to foreign countries or establishing tourism enterprises. They are also migrating to urban areas like Pokhara and Kathmandu, while the new generations are mostly educated and have grown-up outside Lo-manthang. Such a situation is further fueling economic and social migration from Lo-manthang. All of those changes are threatening the Lobas of Lo-manthang to continue indigenous knowledge of agricultural adaptation, ensuring areas food security and food sovereignty, as well as maintaining the Trans-Himalayan habitat and niche.

Acknowledgments We want to thank the University Grants Commission Nepal for partial Financial Support for this research under Ph.D. thesis grants. We would like to thank Prof. Medani Bhandari for his generous support in English Language editing. Similarly, we would like to thank anonymous reviewers of the manuscript.

\section{Authors' contributions}

The first author is the primary researcher. The co-author has supported for framing the paper, analyzing data, and interpreting the results, together with reviewing some literature and refining the manuscript. The author(s) read and approved the final manuscript.

\section{Funding}

University Grants Commission, Nepal, funded partially to conduct this research.

\section{Availability of data and materials}

The data are available.

\section{Ethics approval and consent to participate}

This research involves human participants, human data and human issue. The study was conducted under the 'PhD in Anthropology' project of the first author at Tribhuwan University, Nepal. The University does not had a policy to granting formal ethical approval for the low-risk research idea. The general issues such as obtaining oral consent from the participants before taking their interview, allowing them to leave the interview at any time, and not using any inappropriate means to obtain information were followed. The participants were informed about the research during the observation of their activities. 


\section{Consent for publication}

Not applicable.

\section{Competing interests}

There are no competing interests in this manuscript.

\section{References}

Aase, Tor Halfdan, Ram P. Chaudhary, and Ole R. Vetaas. 2010. Farming flexibility and food security under climatic uncertainty: Manang, Nepal Himalaya: Farming flexibility and food security under climatic uncertainty. Area 42 (2): 228-238 https://doi.org/10.1111/j.1475-4762.2009.00911.x.

Adger, W. Neil. 2000. Social and ecological resilience: Are they related? Progress in Human Geography 24 (3): 347-364 https://doi.org/10.1191/030913200701540465.

Barrows, Harlan H. 1923. Geography as human ecology. Annals of the Association of American Geographers 13 (1): 1-14.

Berkes, Fiket, and Carl Folke. 1998. Linking social and ecological systems for resilience and sustainability. In Linking social and ecological systems: Management practices and social mechanisms for building resilience, ed. Berkes Fiket and Folke Carl, 1-25. Cambridge: Cambridge University Press.

Bhatta, Laxmi D., Bob Eric Helmuth van Oort, Nigel E. Stork, and Himlal Baral. 2015. Ecosystem services and livelihoods in a changing climate: Understanding local adaptations in the upper Koshi, Nepal. International Journal of Biodiversity Science, Ecosystem Services \& Management 11 (2): 145-155 https:// doi.org/10.1080/21513732.2015.1027793.

Bista, Dor Bahadur. 2004. People of Nepal. Kathmandu: Ratna Pustak Bhandar.

Bookchin, Murray. 1995. What is social ecology? In Earth ethics, ed. J. Sterba, 245-259. London: Prenstice Hall.

Capra, Fritjof. 2007. Foreword. In Social learning: Towards a sustainable world, ed. A.E.J. Wals, 13-15. The Netherlands: Wageningen Academic Publishers.

CBS. 2012. National population census 2011 household and population by sex ward level: Mustang. Kathmandu: Central Bureau of Statistics, Government of Nepal.

Chhetri, Netra B., and William E. Easterling. 2010. Adapting to climate change: Retrospective analysis of climate technology interaction in the rice-based farming system of Nepal. Annals of the Association of American Geographers 100 (5): 1156-1176.

Chhetri, Netra, Madhu Subedi, and Sohan Ghimire. 2013. Niche-based responses in addressing the climatic constraints to farm production: Analogues to climate-change adaptation in Nepal. Climate and Development 5 (2): 174-181. https://doi.org/10.1080/17565529.2013.789790.

Chhetri, Purna B. 2006. Sustaining agriculture in upper mustang: Challenges and opportunities. Journal of Sustainable Agriculture 27 (4): 109-124 https://doi.org/10.1300/J064v27n04-08.

Chhetri, Ram B. 2008. Culturally embeded knowledge Inirrigation: People's ways of thriving in a Himalayan Village. In Knowledge systems and natural resources: Management, policyy and institutions in Nepal, ed. Hemant R. Ojha, Netra P. Timsina, Ram B. Chhetri, and Krishna P. Poudel, 135-154. Cambridge University Press India.

Chhetri, Ram B. 2017. Not my relative: Reckoning kinship and relatedness among the Lobas of mustang. In Kinship studies in Nepali anthropology, ed. Laya Prasad Uprety, Binod Pokharel, and Suresh Dhakal, 75-101. Central Department of Anthropology, Tribhuvan University, Nepal.

Crate, Susan A., and Mark Nuttall. 2016. Introduction: Anthropology and climate change. In Anthropology and climate change: From actions to transformations, 11-34. New York: Routledge, Taylor \& Francis Group.

Cruz, R.V., H. Harasawa, M. Lal, S. Wu, Y. Anokhin, B. Punsalmaa, Y. Honda, M. Jafari, C. Li, and N. Huu Ninh. 2007. Asia. In Climate change 2007: Impacts, adaptation and vulnerability, contribution of working group II to the fourth assessment report of the intergovernmental panel on climate change, ed. 
M.L. Parry, O.F. Canziani, J.P. Palutikof, P.J. van der Linden, and C.E. Hanson, 469-506. Cambridge: Cambridge University Press.

DDC, Mustang. 2068. District profile of mustang, 2068 (in Nepali Mustang Jillako Bastugat Bibaran, 2068). Nepal: DDC, Mustang.

Dhungel, Ramesh. 2002. The Kingdom of Lo (Mustang): A historical study. 1st ed. Kathmandu: Tashi Gephel Foundation.

Fort, Monique. 2015. Natural hazards versus climate change and their potential impacts in the dry, northern Himalayas: Focus on the upper Kali Gandaki (Mustang District, Nepal). Environmental Earth Sciences 73 (2): 801-814. https://doi.org/10.1007/s12665-014-3087-y.

Gentle, Popular, Rik Thwaites, Digby Race, and Kim Alexander. 2014. Differential impacts of climate change on communities in the middle hills region of Nepal. Natural Hazards 74: 815-836. https://doi. org/10.1007/s11069-014-1218-0.

Gills, Barry, and Jamie Morgan. 2020. Global climate emergency: After COP24, climate science, urgency, and the threat to humanity. Globalizations 17 (6): 885-902 https://doi.org/10.1080/14747731.2019. 1669915 .

Hardesty, Donald L. 1975. The niche concept: Suggestions for its use in human ecology. Human Ecology 3 (2): 71-85 https://doi.org/10.1007/BF01552263.

Harris, M. 1975. Culture, people, nature: An introduction to general anthropology. 2nd ed. New York: Crowell.

IPCC. 2018. Intergovernmental panel on climate change. 2018. Global warming of $1.5^{\circ} \mathrm{C}$ : An IPCC special report. Geneva: IPCC.

IPCC. 2019. Intergovernmental panel on climate change. Climate change and land. Geneva: IPCC.

Kassam, Karim-Aly, Munira Karamkhudoeva, Morgan Ruelle, and Michelle Baumflek. 2010. Medicinal plant use and health sovereignty: Findings from the Tajik and Afghan Pamirs. Human Ecology 38 (6): 817829 https://doi.org/10.1007/s10745-010-9356-9.

Kassam, Karim-Aly S. 2009. Biocultural diversity and indigenous ways of knowing: Human ecology in the Arctic, Northern lights series, no. 12. Calgary: University of Calgary Press.

Kaufmann, Robert K., Michael L. Mann, Sucharita Gopal, Jackie A. Liederman, Peter D. Howe, Felix Pretis, Xiaojing Tang, and Michelle Gilmore. 2017. Spatial heterogeneity of climate change as an experiential basis for skepticism. Proceedings of the National Academy of Sciences 114 (1): 67-71 https://doi.org/10. 1073/pnas.1607032113.

Khattri, Man Bahadur. 2019. Climate change, crops, livestock, and human relations to food sovereignty among the Loba of Nepal. In Conference proceedings 2015, 42-62. Kathmandu: Social Scince Baha.

Kitchin, Rob, and Mark Blades. 2002. The cognition of geographic space. London: Tauris.

Lawrence, Roderick J. 2003. Human ecology and its applications. Landscape and Urban Planning 65 (1-2): 31-40 https://doi.org/10.1016/S0169-2046(02)00235-9.

Little, Michael A. 2007. Human ecology in anthropology: Past, present, and prospects. In Anthropology today: Trends, scope and applications, ed. V. Bhasin and M.K. Bhasin, 25-38. Delhi: Kamal Raj Enterprises.

Macchi, Mirjam, Amanda Manandhar Gurung, and Brigitte Hoermann. 2015. Community perceptions and responses to climate variability and change in the Himalayas. Climate and Development 7 (5): 414-425 https://doi.org/10.1080/17565529.2014.966046.

Manandhar, Sujata, Dietrich Schmidt Vogt, Sylvain R. Perret, and Futaba Kazama. 2011. Adapting cropping systems to climate change in Nepal: A cross-regional study of farmers' perception and practices. $R e$ gional Environmental Change 11 (2): 335-348 https://doi.org/10.1007/s10113-010-0137-1.

Moench, Marcus. 2007. Adapting climate change and risks associated with other natural hazards: Methods for moving from concept to action. In Working with the winds of change: Toward strategies for responding to the risks associated with climate change and other hazards, 2nd ed., 14-48. Kathmandu: Published by Provention Consortium, Institute for Social and Environmental Transition-International, and Institute for Social and Environmental Transition--Nepal.

Ojha, Durga Prasad. 1986. The economy of mustang: Lo region. Kathmandu: Centre for Nepal \& Asian Studies Tribhuvan University.

Onta, Nisha, and Bernadette P. Resurreccion. 2011. The role of gender and caste in climate adaptation strategies in Nepal: Emerging change and persistent inequalities in the far-western region. Mountain Research and Development 31 (4): 351-356 https://doi.org/10.1659/MRD-JOURNAL-D-10-00085.1.

Orlove, B.S. 1980. Ecological anthropology. Annual Review of Anthropology 9 (1): 235-273 https://doi.org/ 10.1146/annurev.an.09.100180.001315. 
Palazzoli, I., S. Maskey, S. Uhlenbrook, E. Nana, and D. Bocchiola. 2015. Impact of prospective climate change on water resources and crop yields in the Indrawati basin, Nepal. Agricultural Systems 133: 143157. https://doi.org/10.1016/j.agsy.2014.10.016.

Pandey, R. 2019b. Farmers' perception on agro-ecological implications of climate change in the MiddleMountains of Nepal: A case of Lumle Village, Kaski, environment. Development and Sustainability (Springer) 21 (1): 221-247 https://link.springer.com/article/10.1007/s10668-017-0031-9.

Pandey, Rishikesh. 2013. Development and environment: An assessment of population growth vis-a-vis soil erosion in Nepal. Dhawalagiri Journal of Sociology and Anthropology 7: 173-196.

Pandey, Rishikesh. 2016a. Dynamics of the Himalayan climate: A study of the Kaligandaki Basin, Nepal. Pertanika Journal of Social Sciences and Humanities (A publication of Universiti Putra Malaysia UPM) 24 (2): 737-756.

Pandey, Rishikesh. 2016b. Human ecological implication of climate change in the Himalaya: Investigating opportunities for adaptation in the Kaligandaki Basin, Nepal. Ph.D. Thesis, the University of Adelaide, Australia Available at: http://hdl.handle.net/2440/99095.

Pandey, Rishikesh. 2017. Life and livelihoods in the forbidden kingdom, the trans-Himalaya, Nepal. Dhawalagiri Journal of Sociology and Anthropology 11: 24-59 https://doi.org/10.3126/dsaj.v11i0.18822.

Pandey, Rishikesh. 2019a. Climate change impacts and adaptation response: A study of trans-Himalaya (upper-mustang), Nepal. In Conference proceedings 2016: The annual Kathmandu conference on Nepal and the Himalaya, 145-179. Kathmandu: Social Science Baha ISBN: 978-9937-597-48-7, https://soscbaha.org/ebook/conference-proceedings-2016/.

Pandey, Rishikesh, and Douglas K. Bardsley. 2019. An application of the household food insecurity access scale to assess food security in rural communities of Nepal. Asia \& the Pacific Policy Studies 6 (2): 130-150 https://doi.org/10.1002/app5.270.

Paudel, Keshav Prasad, and Peter Andersen. 2012. Response of rangeland vegetation to snow cover dynamics in Nepal trans Himalaya. Climatic Change 117 (1-2): 149-162 https://doi.org/10.1007/s10584-0120562-X.

Peissel, M. 1992. Mustang: A lost Tibetan kingdom (1. reprint). Delhi: Book Faith India.

Polanyi, Karl, Cornard Arensberg, and Pearson, Harry. W. 1957. Trade and market in the early empires. Glencoe: Free Press.

Prudham, Scott. 2009. Human ecology. In The dictionary of human geography, ed. D. Gregory, R. Johnston, G. Pratt, G.M.J. Watts, and S. Whatmore, 5th ed., 348-349. USA: Wiley-Blackwell viewed 25 March, 2012.

Rappaport, Roy A. 1967. Pigs for the ancestors. New Haven: Yale Univ. Press.

Ripple, William J., Christopher Wolf, Thomas M. Newsome, Phoebe Barnard, and William R. Moomaw. 2019. World scientists' warning of a climate emergency. BioScience November: biz088 https://doi.org/ 10.1093/biosci/biz088.

Service, Elman. 1962. Primitive social organization: An evolutionary approach. New York: Random House.

Sharma, Eklabya, Nakul Chettri, Karma Tsering, Arun B. Shrestha, Fang Jing, Pradeep Mool, and Mmats Eriksson. 2009. Climate change impacts and vulnerability in the eastern Himalayas. Kathmandu: ICIMOD.

Sherpa, Pasang. 2014. Climate change, perceptions, and social heterogeneity in Pharak, Mount Everest region of Nepal. Human Organization 73 (2): 153-161 https://doi.org/10.17730/humo.73.2.94q43152111733t6.

Shrestha, Uttam Babu, Shiva Gautam, and Kamaljit S. Bawa. 2012. Widespread climate change in the Himalayas and associated changes in local ecosystems. Edited by Gil Bohrer. PLoS One 7 (5): e36741 https:// doi.org/10.1371/journal.pone.0036741.

Steward, Julian H. 1977. Evolution and ecology: Essays on social transformation. Urbana: University of Illinois Press.

Sutton, Mark Q., and E.N. Anderson. 2009. Introduction to cultural ecology. Rowman Altamira.

Sutton, Mark Q., and E.N. Anderson. 2010. Introduction to cultural ecology. 2nd ed. Lanham: AltaMira Press.

Suwal, Bhim Raj. 2014. Internal migration in Nepal. In Population monographs of Nepal, 1:241-83. Kathmandu: Government of Nepal, National Planning Commission Secretariat, Central Bureau of Statistics.

Uprety, Laya Prasad. 2005. Cultural ecology of the Highland communities: Some anthropological observations from eastern Nepal. Dhaulagiri Journal of Sociology and Anthropology 1 (0): 1-32 https://doi.org/ 10.3126/dsaj.v1i0.273. 
Vayda, Andrew P. 1983. Progressive contextualization: Methods for research in human ecology. Human Ecology 11 (3): 265-281 http://www.jstor.org/stable/4602704.

Vayda, Andrew. P. 1974. Warfare in ecological perspective. Annual Review of Ecology and Systematics 5 (1): 183-193 https://doi.org/10.1146/annurev.es.05.110174.001151.

Watts, M.J. 2009. Adaptation. In The dictionary of human geography, ed. D. Gregory, R. Johnston, G. Pratt, G.M.J. Watts, and S. Whatmore, 5th ed., 7-8. USA: Wiley-Blackwell viewed 26 March, 2012.

Wester, Philippus, Arabinda Mishra, Aditi Mukherji, and Arun Bhakta Shrestha, eds. 2019. The Hindu Kush Himalaya: Assessment Mountains, climate change, sustainability and people. Kathmandu: ICIMOD.

White, Leslie A. 1959. The evolution of culture. New York: McGraw-Hill.

Yeh, Emily T., Yonten Nyima, Kelly A. Hopping, and Julia A. Klein. 2014. Tibetan pastoralists' vulnerability to climate change: A political ecology analysis of snowstorm coping capacity. Human Ecology 42 (1): 61-74 https://doi.org/10.1007/s10745-013-9625-5.

\section{Publisher's Note}

Springer Nature remains neutral with regard to jurisdictional claims in published maps and institutional affiliations. 